ARTICLE

\title{
High pressure synthesis of phosphine from the elements and the discovery of the missing $\left(\mathrm{PH}_{3}\right)_{2} \mathrm{H}_{2}$ tile
}

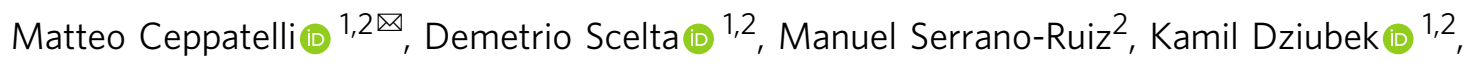
Gaston Garbarino (1) ${ }^{3}$, Jeroen Jacobs ${ }^{3}$, Mohamed Mezouar (10 ${ }^{3}$, Roberto Bini ([) ${ }^{1,2,4}$ \& Maurizio Peruzzini ${ }^{2}$

High pressure reactivity of phosphorus and hydrogen is relevant to fundamental chemistry, energy conversion and storage, and materials science. Here we report the synthesis of $\left(\mathrm{PH}_{3}\right)_{2} \mathrm{H}_{2}$, a crystalline van der Waals (vdW) compound $(14 \mathrm{~cm})$ made of $\mathrm{PH}_{3}$ and $\mathrm{H}_{2}$ molecules, in a Diamond Anvil Cell by direct catalyst-free high pressure (1.2 GPa) and high temperature $(T \lesssim 1000 \mathrm{~K}$ ) chemical reaction of black phosphorus and liquid hydrogen, followed by room T compression above $3.5 \mathrm{GPa}$. Group 15 elements were previously not known to form $\mathrm{H}_{2}$-containing vdW compounds of their molecular hydrides. The observation of $\left(\mathrm{PH}_{3}\right)_{2} \mathrm{H}_{2}$, identified by synchrotron X-ray diffraction and vibrational spectroscopy (FTIR, Raman), therefore represents the discovery of a previously missing tile, specifically corresponding to $P$ for pnictogens, in the ability of non-metallic elements to form such compounds. Significant chemical implications encompass reactivity of the elements under extreme conditions, with the observation of the $P$ analogue of the Haber-Bosch reaction for $N$, fundamental bond theory, and predicted high pressure superconductivity in P-H systems.

\footnotetext{
${ }^{1}$ LENS, European Laboratory for Non-linear Spectroscopy, Via N. Carrara 1, I-50019 Firenze, Sesto Fiorentino, Italy. ${ }^{2}$ ICCOM-CNR, Institute of Chemistry of OrganoMetallic Compounds, National Research Council of Italy, Via Madonna del Piano 10, I-50019 Firenze, Sesto Fiorentino, Italy. ${ }^{3}$ ESRF, European Synchrotron Radiation Facility, 71 Avenue des Martyrs, 38000 Grenoble, France. ${ }^{4}$ Dipartimento di Chimica "Ugo Schiff" dell'Università degli Studi di Firenze,

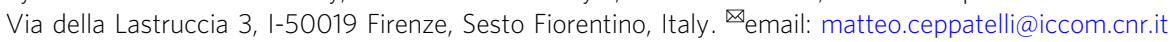


T he history of the layered structures of phosphorus has been intimately related to pressure since $1914^{1}$, when Percy Bridgman, who may be considered the founder of high pressure science, first synthesized black phosphorus $\left(\mathrm{P}_{\text {black }}\right)$, whose characteristic crystalline layered structure corresponds to the thermodynamically stable allotrope of the element ${ }^{2}$. Rhombohedral A7, another layered structure of phosphorus, was later discovered by compression of $\mathrm{P}_{\text {black }}$ above $5 \mathrm{GPa}^{3}$. Recently, a high pressure study, based on synchrotron X-ray diffraction (XRD) in Diamond Anvil Cell (DAC), has made another mark in the history of the layered structures of phosphorus, providing a clear insight about the mechanism of interlayer bond formation and significantly raising the pressure limit for the existence of the phosphorus layers up to $\sim 30 \mathrm{GPa}$ at room $\mathrm{T}^{4,5}$.

In 2014, the advent of phosphorene ${ }^{6}$, a $2 \mathrm{D}$ corrugated monoatomic layer of phosphorus atoms with extraordinary properties, whose stacking actually builds up the the crystal structure of $\mathrm{P}_{\text {black, }}$, has sharply raised the attention of the scientific community about the layered structures of element 15 , with considerable experimental and theoretical efforts nowadays in attempting to stabilize and functionalize the phosphorus layers by the introduction of molecular fragments ${ }^{7}$ or atoms, like for example $\mathrm{H}^{8}$.

During the last two decades, the generation of pressure in the GPa range has greatly expanded the horizon of chemistry under extreme conditions 9 . In particular, the combination of pressure with high temperature or electronic photo-excitation has been shown to be a very effective and extremely powerful tool for opening selective reactive paths $s^{10,11}$, activating chemical reactivity in notoriously non interacting systems at ambient conditions ${ }^{12}$, like here $\mathrm{P}$ and $\mathrm{H}$, and for synthesizing new unexpected compounds ${ }^{13,14}$, thus suggesting the idea of investigating the so far unexplored chemistry of the phosphorus-hydrogen system under high pressure conditions.

Besides $\mathrm{H}$-functionalization and stabilization of the layered structures of phosphorus, the direct chemical reactivity between elemental phosphorus and hydrogen under high pressure conditions is indeed currently of extreme interest for relevant issues essentially related to the chemistry and physics of phosphorus hydrides. Molecular hydrides of non-metallic elements have indeed always attracted the attention of high pressure chemists, physicists and materials scientists for their potential applications as superconducting ${ }^{15}$ and $\mathrm{H}$-storage materials, due to their high $\mathrm{H}$ content and to the ability of forming stoichiometric van der Waals (vdW) compounds in the presence of $\mathrm{H}_{2}{ }^{16,17}$. Since the first report of a vdW solid made of $\mathrm{He}$ and $\mathrm{N}_{2}{ }^{18}$, many $\mathrm{H}_{2}$ containing vdW compounds involving elements from group 14 to group 18, including nobles gases, simple diatomics and molecular hydrides of non-metallic elements, have been experimentally observed at high pressure: $\mathrm{CH}_{4}\left(\mathrm{H}_{2}\right)_{4}{ }^{19}, \mathrm{CH}_{4} \mathrm{H}_{2}{ }^{19},\left(\mathrm{CH}_{4}\right)_{2} \mathrm{H}_{2}{ }^{19}$, $\left.\mathrm{SiH}_{4}\left(\mathrm{H}_{2}\right)_{2}{ }^{20}, \mathrm{GeH}_{4}\left(\mathrm{H}_{2}\right)_{2}{ }^{21}, \quad \mathrm{~N}_{2}\left(\mathrm{H}_{2}\right)_{2}\right)^{22}, \quad\left(\mathrm{~N}_{2}\right)_{6}\left(\mathrm{H}_{2}\right)_{7}^{22,23}$, $\left(\mathrm{O}_{2}\right)_{3}\left(\mathrm{H}_{2}\right)_{4}{ }^{24},\left(\mathrm{H}_{2} \mathrm{O}\right)_{6} \mathrm{H}_{2}{ }^{25},\left(\mathrm{H}_{2} \mathrm{O}\right) \mathrm{H}_{2}{ }^{25},\left(\mathrm{H}_{2} \mathrm{~S}\right)_{2} \mathrm{H}_{2}{ }^{26},\left(\mathrm{H}_{2} \mathrm{Se}\right)_{2} \mathrm{H}_{2}{ }^{27}$, $(\mathrm{HI})_{2} \mathrm{H}_{2}{ }^{28}, \operatorname{Ar}\left(\mathrm{H}_{2}\right)_{2}{ }_{2}^{29}, \operatorname{Kr}\left(\mathrm{H}_{2}\right)_{2}{ }^{30}, \mathrm{Xe}\left(\mathrm{H}_{2}\right)_{8}{ }^{31,32}$. Nevertheless, among those formed by $\mathrm{H}_{2}$ and by the molecular hydride of a non-metallic element reported so far, none involves any of group 15 elements $^{33}$. Within this picture, if the elements in the periodic table are to be considered tiles arranged on the basis of their electronic configuration, which determines their properties, then group 15 elements, named pnictogens, represent the missing tiles in this arrangement.

Phosphorus is here of particular relevance. Indeed the recent discovery of high superconducting $T_{\mathrm{c}}$ of $203 \mathrm{~K}$ in $\mathrm{H}_{2} \mathrm{~S}$ at high pressure $^{34}$, in agreement with the Bardeen-Cooper-Schrieffer (BCS) phonon mediated theory of high temperature superconductivity ${ }^{35}$, has further promoted the search for a similar behavior in the hydrides of neighbor elements in the periodic table. In particular, in the case of phosphorus the report of high pressure

superconductivity in phosphine $\left(T_{\mathrm{c}}>100 \mathrm{~K}, \mathrm{P}>200 \mathrm{GPa}\right)^{36}$, has stimulated several theoretical studies aimed at exploring the structure and stability of $\mathrm{PH}_{3}$ at high pressure and the substantially unknown high pressure behavior of the phosphorus-hydrogen system, with the prediction of superconducting layered structures formed by these two elements above $80 \mathrm{GPa}^{37-39}$.

Finally, the formation, stability and decomposition of $\mathrm{PH}_{3}$ in presence of $\mathrm{H}_{2}$ are relevant astrochemical issues ${ }^{40}$ related to the composition of giant planets, such as Jupiter and Saturn ${ }^{41,42}$, and their moons ${ }^{43}$, where $\mathrm{PH}_{3}$ and $\mathrm{H}_{2}$ have been detected.

Within this picture, in this paper we report a synchrotron XRD and vibrational spectroscopy (FTIR and Raman) study of the high pressure chemistry occurring between black phosphorus and molecular hydrogen at pressure of $1.2-1.5 \mathrm{GPa}$ and temperature $\$ 1000 \mathrm{~K}$, where phosphorus is in the layered crystalline orthorhombic structure (A17), commonly known as black phosphorus, and $\mathrm{H}_{2}$ is liquid ${ }^{44}$ (Fig. 1). In these thermodynamic conditions $\mathrm{PH}_{3}$ is directly synthesized from the elements. On further room T compression, between 3.5 and $4.1 \mathrm{GPa}, \mathrm{PH}_{3}$ combined with

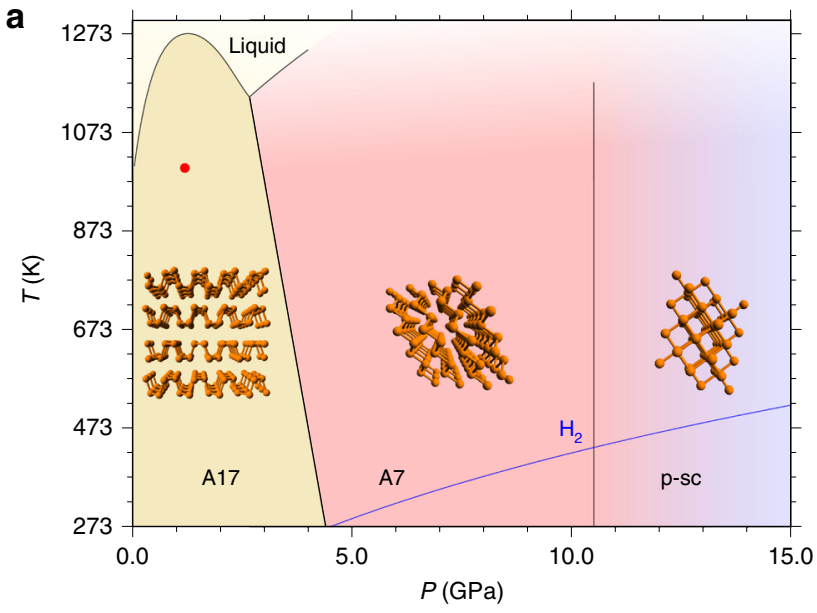

b

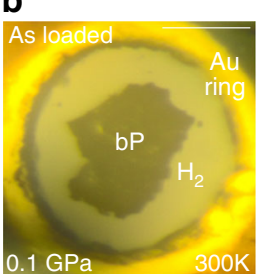

c

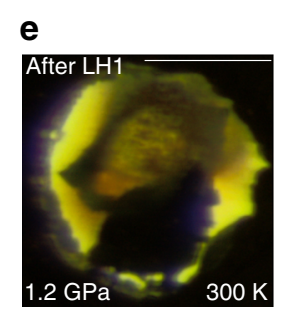

Fig. 1 Phase diagram and reactivity of $P$ and $\mathrm{H}_{2}$ at high pressure and high temperature. a Phase diagram of phosphorus (black lines), showing the stability regions of the orthorhombic $\left(A 17, P_{\text {black }}\right)$, rhombohedral $(A 7)$ and pseudo simple-cubic ( $p$-sc) structures ${ }^{4,5}$. The melting line of $\mathrm{H}_{2}{ }^{73}$ (blue line) and laser heating conditions (red point at $P=1.2 \mathrm{GPa}, \mathrm{T} \approx 1000 \mathrm{~K}$ ) are also displayed. b-g Microphotographs showing the sample aspect after loading (b), before, during and after LH1 (c-e), after $\mathrm{LH} 2$ (f), and after $\mathrm{LH} 3$ (g) at pressure ranging between 1.2 and $1.5 \mathrm{GPa}(\mathrm{LH} 1, \mathrm{LH} 2$, and $\mathrm{LH} 3$, respectively, indicate the first, the second and the third laser heating). The scale bars in the top right corner of $\mathbf{b}$, e correspond to $100 \mu \mathrm{m}$. 

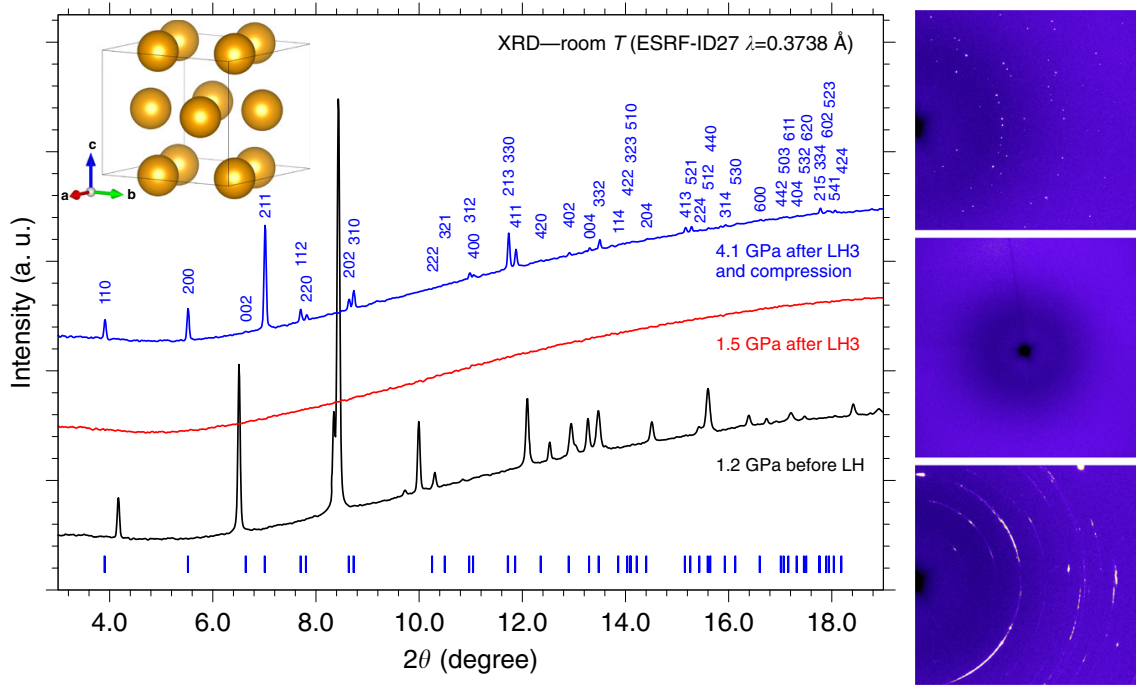

Fig. 2 X-ray diffraction. Integrated panoramic XRD patterns and corresponding detector images of the sample, acquired at room T before laser heating $(\mathrm{LH})$ at $1.2 \mathrm{GPa}$ (black trace, bottom image), after the third laser heating (LH3) at $1.5 \mathrm{GPa}$ (red trace, middle image), and after compression at $4.1 \mathrm{GPa}$ (blue trace, top image). The blue ticks and labels respectively refer to the refined peak positions of the crystalline product at this pressure (Supplementary Note 1) and to the corresponding $h, k, l$ indexing. The tetragonal $/ 4 \mathrm{~cm}$ structure of $\mathrm{P}$ atoms as obtained from single-crystal data at $5.5 \mathrm{GPa}$ is also shown in the top left corner of the Figure (see the "X-Ray Diffraction" section).

excess $\mathrm{H}_{2}$ to form the crystalline vdW compound $\left(\mathrm{PH}_{3}\right)_{2} \mathrm{H}_{2}$, whose identification has remarkable implications. Pressure was statically generated by means of membrane DAC and temperature by laser heating $(\mathrm{LH})$, with $\mathrm{P}_{\text {black }}$ acting at the same time as reactant and laser absorber and $\mathrm{H}_{2}$ as a reactant and pressure transmitting medium.

\section{Results}

X-Ray Diffraction. After loading (see "Methods"), the sample of $\mathrm{P}_{\text {black }}$ and $\mathrm{H}_{2}$ was compressed to $1.2 \mathrm{GPa}$, where three laser irradiations were performed. The irradiations power $(<3 \mathrm{~W}$ at laser output) and duration (up to $\sim 30 \mathrm{~s}$ ) were carefully increased up to visually observe the real time chemical transformation of the sample, which occurred in the $900 \pm 100 \mathrm{~K}$ temperature interval, with only a slight pressure drift from 1.2 to $1.3 \mathrm{GPa}$, and then to $1.5 \mathrm{GPa}$, respectively, after the second (LH2) and third (LH3) irradiation (Fig. 1).

Each irradiation produced an increasing transformation of $\mathrm{P}_{\text {black }}$, as confirmed by the intensity decrease of the $\mathrm{P}_{\text {black }}$ peaks in the diffraction patterns acquired before and after laser heating. After LH3 the absence of diffraction peaks indicated the complete consumption of $\mathrm{P}_{\text {black }}$, suggesting the formation of an amorphous or liquid product in the laser heated area (Fig. 2).

The sample was then compressed at room $\mathrm{T}$ and between 3.5 and $4.1 \mathrm{GPa}$ the sudden appearance of single diffraction spots in the detector image, observed up to the highest explored pressure $(5.5 \mathrm{GPa})$, unambiguously marked the formation of a crystalline product (Fig. 2). A careful XRD mapping of the sample over a grid with $10 \mu \mathrm{m}$ spacing was performed to identify the regions where single spot diffraction could be observed. These regions were further explored by higher resolution mapping $(4 \mu \mathrm{m}$ spacing grid) and single-crystal patterns acquired on selected points of the laser heated area.

As $\mathrm{H}_{2}$ is liquid below $5.7 \mathrm{GPa}$ (Fig. 1) and $\mathrm{H}$ atoms are weak Xray scatterers, only information about the $\mathrm{P}$ atoms could be evinced from our single-crystal data, whose structure solution at $5.5 \mathrm{GPa}$ indicates a tetragonal structure $(a=7.6075(6) \AA, b=7.6075(6) \AA$, $c=6.3303(13) \AA, \alpha=90^{\circ}, \beta=90^{\circ}, \gamma=90^{\circ}, V=366.36(9) \AA^{3}, Z=$ 8) belonging to space group $I 4 \mathrm{~cm}\left(\mathrm{n} .108, C_{4 \mathrm{v}}^{10}\right)$, where the shortest distance between $\mathrm{P}$ atoms is $3.608 \AA$ (Fig. 2 and Supplementary
Note 1) and which does not correspond to any known structure of phosphorus. An equivalent solution corresponding to centrosymmetric space group $I 4 / \mathrm{mcm}$ (n. $140, \mathrm{D}_{4 h}^{18}$ ) was initially considered (see "Discussion").

The first reaction product that we thought about was of course $\mathrm{PH}_{3}$. Unfortunately, even if $\mathrm{PH}_{3}$ is expected to solidify at higher pressure with respect to $\mathrm{NH}_{3}(1.0 \mathrm{GPa})$ due to the smaller electric dipole moment and to the absence of $\mathrm{H}$-bonding 45,46 , the solidification pressure of $\mathrm{PH}_{3}$ at room $\mathrm{T}$ is unknown.

Furthermore, the high pressure structure of solid $\mathrm{PH}_{3}$ is also unknown and only ambient pressure low T XRD data by Natta and Casazza dating back to $1930^{47}$ are available in the literature, indicating that $\mathrm{PH}_{3}$ crystallizes into a compact packing face centered cubic structure, possibly belonging to space group $T_{\mathrm{h}}^{2}$ $\left(P n \overline{3}, P 2 / n \overline{3}\right.$, n. 201) or $O_{\mathrm{h}}^{4}\left(P n \overline{3} m, P 4_{2} / n \overline{3} 2 / m\right.$, n. 224), none of which is compatible with our single-crystal data (Supplementary Note 2).

Even considering the $\mathrm{P}$ positions in the $I 4 \mathrm{~cm}$ and $I 4 / \mathrm{mcm}$ structures obtained from the single-crystal data as occupied by $\mathrm{PH}_{3}$ molecules, some inconsistencies emerge with a compact packing structure. Indeed, assuming orientationally disordered spherical shaped $\mathrm{PH}_{3}$ molecules in contact with each other, deriving the molecular volume using as molecular radius half of the shortest distance between $\mathrm{P}$ atoms $\left((4 / 3) \pi(3.608 / 2)^{3}=24.592 \AA^{3}\right.$, in agreement with literature $\left.{ }^{48,49}\right)$, and considering 8 molecules per unit cell, then a filled volume of $196.736 \AA^{3}$ out of the $366.36 \AA^{3}$ unit cell volume obtained from the single-crystal data can be estimated, corresponding to a 0.537 filling ratio, which is significantly lower than the 0.74 ratio expected for a close packing structure.

This occurrence, indicating the presence of free volume, which can not be accounted for by a compact packing of $\mathrm{PH}_{3}$, provided the first hints suggesting the presence of interactions between $\mathrm{PH}_{3}$ molecules and a different composition of our reaction product, as indeed confirmed by the spectroscopic data.

Fourier Transform InfraRed absorption spectroscopy. The Fourier Transform InfraRed (FTIR) spectra acquired after LH3 at 6.7 $\mathrm{GPa}$ and at different pressures during decompression are shown in Fig. 3 with the relevant band frequencies listed in Table 1. At 6.7 GPa, infrared absorption maxima are observed 
a
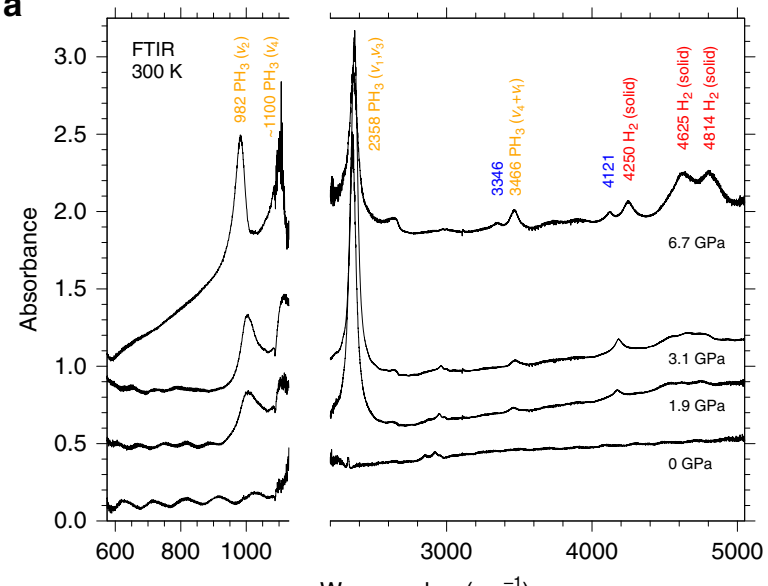

Wavenumber $\left(\mathrm{cm}^{-1}\right)$

b

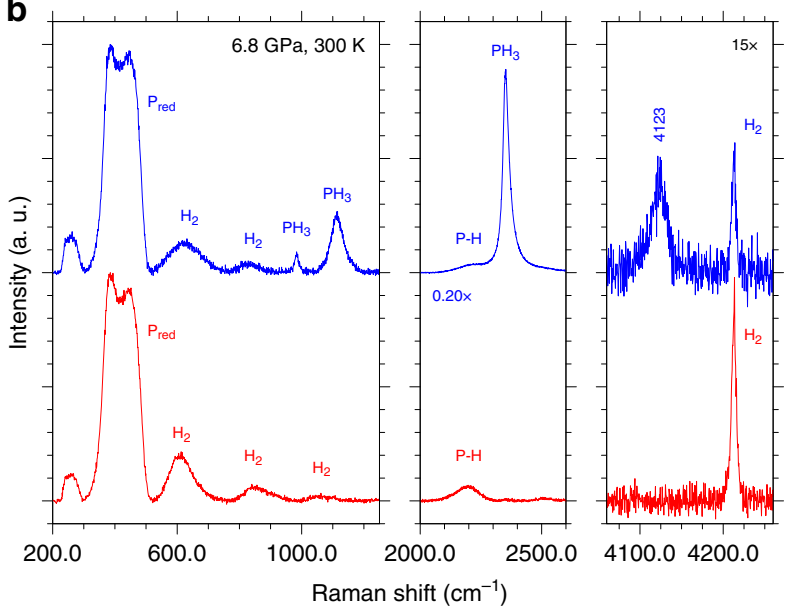

Fig. 3 FTIR and Raman spectroscopy. a Room T FTIR absorption spectra of the sample acquired at $6.7 \mathrm{GPa}$ after LH3 and at different pressure values during decompression to ambient conditions. The two bands at 3346 and $4121 \mathrm{~cm}^{-1}$ labeled in blue disappear on releasing pressure to $3.1 \mathrm{GPa}$.

The spectra have been vertically translated for clarity and the values on the absorbance scale are intended for relative comparison. The break on the wavenumber axis excludes the spectral range corresponding to the la diamond saturating absorptions, which partially covers the $\nu_{4}$ absorption of $\mathrm{PH}_{3}$. The absorption features at $\sim 2640 \mathrm{~cm}^{-1}(6.7 \mathrm{GPa})$ and $\sim 2900 \mathrm{~cm}^{-1}$ (appearing on releasing pressure to $3.1 \mathrm{GPa}$ ) are assigned respectively to the diamond from the ambient pressure reference and to traces of oil on the optics of the interferometer. $\mathbf{b}$ Significant spectral regions of type-1 (red, lower trace) and type-2 (blue, upper trace) Raman spectra acquired on different selected spots of the mapping grid across the sample at 6.8 $\mathrm{GPa}$ and room T after $\mathrm{LH}$. With respect to type-1 spectrum the type-2 one clearly shows the simultaneous presence of $\mathrm{PH}_{3}$ and of the extra band at $4123 \mathrm{~cm}^{-1}$ in the $\mathrm{H}_{2}$ stretching region at lower frequency compared to pure $\mathrm{H}_{2}$.

at $983, \sim 1100$ (out of scale) $2358,3346,3466,4121,4250,4625$, and $4814 \mathrm{~cm}^{-1}$.

The last three bands can be assigned to infrared active absorptions of $\mathrm{H}_{2}\left(4250\left(\mathrm{Q}_{1}(1), 4625\left(\mathrm{Q}_{1}(1)+\mathrm{S}_{0}(0)\right)\right.\right.$, and 4814 $\left.\left(\mathrm{Q}_{1}(1)+\mathrm{S}_{0}(1)\right) \mathrm{cm}^{-1}\right)$ in agreement with literature ${ }^{44}$.

Even if the infrared bands of solid $\mathrm{PH}_{3}$ have been measured only at low $\mathrm{T}^{50,51}$ and those of liquid $\mathrm{PH}_{3}$ only at low temperature and modest high pressure (up to $35 \mathrm{~atm})^{52}$, the bands observed at 983, 1100,2358 , and $3466 \mathrm{~cm}^{-1}$ can be confidently assigned to the fundamental and combination vibrational modes of $\mathrm{PH}_{3}$, as indicated in Table 1.
Finally, the two remaining bands at 3346 and $4121 \mathrm{~cm}^{-1}$ can not be assigned either to $\mathrm{PH}_{3}$ or $\mathrm{H}_{2}$ (Supplementary Note 3).

On decompression from 6.7 to $3.1 \mathrm{GPa}$, below the crystallization threshold of the reaction product, the two extra bands at $3346 \mathrm{~cm}^{-1}$ and $4121 \mathrm{~cm}^{-1}$ disappear. All the other bands of $\mathrm{PH}_{3}$ exhibit a high-frequency shift, as typically observed in $\mathrm{H}$-bonded systems when releasing pressure, and the bands of $\mathrm{H}_{2}$ a lowfrequency shift, as expected. On further decompression to ambient conditions, both $\mathrm{PH}_{3}$ and $\mathrm{H}_{2}$ bands shift to lower frequency, until disappearing with the opening of the cell.

No bands could be detected in the FTIR spectra after completely releasing the membrane pressure and opening/closing the cell under glove box in an inert atmosphere.

Raman spectroscopy. A detailed Raman mapping, consisting of a $130 \times 130 \mu \mathrm{m}^{2}$ mesh with $10 \mu \mathrm{m}$ grid spacing, was performed to gain insight about the reaction products and their spatial distribution within the sample at each pressure point during decompression, covering the entire frequency range between 40 and $4700 \mathrm{~cm}^{-1}$. The analysis of the Raman spectra acquired across the sample at $6.8 \mathrm{GPa}$ revealed the presence of two limit spectra, referred to in the following respectively as type- 1 and type-2 Raman spectra, and a variety of combinations of them, with significant bands in three spectral regions: $200-1250 \mathrm{~cm}^{-1}$, 2000-2600 $\mathrm{cm}^{-1}$, and $4000-4300 \mathrm{~cm}^{-1}$ (Fig. 3 and Supplementary Fig. 5).

Type-1 Raman spectrum (Fig. 3, lower panel, red trace) exhibits broad bands at $388,449,613,833,1064,2198,2520$, and $4212 \mathrm{~cm}^{-1}$, whereas in type- 2 Raman spectrum additional bands are detected at $984,1114,2352,4123 \mathrm{~cm}^{-1}$. The two broad features observed in all the spectra at 388 and $449 \mathrm{~cm}^{-1}$ can be assigned to amorphous $\mathrm{P}_{\text {red }}$ (Supplementary Note 5). The weak band at $2198 \mathrm{~cm}^{-1}$, which has significantly lower frequency compared to phosphine $\left(\mathrm{PH}_{3} 2321 \mathrm{~cm}^{-1}\right)^{52}$, or to higher phosphane homologues like diphosphane $\left(\mathrm{P}_{2} \mathrm{H}_{4} 2283 \mathrm{~cm}^{-1}\right)^{53}$ and triphosphane $\left(\mathrm{P}_{3} \mathrm{H}_{5} 2267 \mathrm{~cm}^{-1} \text { at } 193 \mathrm{~K}\right)^{53}$, is compatible with the typical vibrational frequency of $\mathrm{P}-\mathrm{H}$ bonds and further confirms the occurrence of chemical reactivity between $\mathrm{P}$ and $\mathrm{H}_{2}$. The sharp band at $4212 \mathrm{~cm}^{-1}$ identifies the characteristic stretching vibration of $\mathrm{H}_{2}$ and those at 613,833 , and $1064 \mathrm{~cm}^{-1}$ the corresponding pressure broadened $\mathrm{S}_{0}(1), \mathrm{S}_{0}(2)$, and $\mathrm{S}_{0}(3)$ rotational bands $\left(\mathrm{S}_{0}(0) \text { overlaps with the band of } \mathrm{P}_{\text {red }} \text { at } 388 \mathrm{~cm}^{-1}\right)^{54}$.

Type-2 Raman spectrum exhibits additional bands at 984, 1114 , and $2352 \mathrm{~cm}^{-1}$, which can be readily assigned respectively to the $v_{2}, v_{4}$ and $v_{1}: v_{3}$ fundamental modes of $\mathrm{PH}_{3}{ }^{51}$, consistently with the IR spectra (Fig. 3, lower panel, blue trace). However, differently from the IR spectra, no combination bands of $\mathrm{PH}_{3}$ are detected in the Raman spectra. The Raman band at $4123 \mathrm{~cm}^{-1}$, observed only in type-2 Raman spectra together with the presence of $\mathrm{PH}_{3}$, almost exactly matches the corresponding IR absorption band at $4121 \mathrm{~cm}^{-1}(6.7 \mathrm{GPa})$ and can not be assigned either to $\mathrm{P}$, $\mathrm{H}_{2}$ or $\mathrm{PH}_{3}$.

As in the case of the IR spectra, during decompression to $3.1 \mathrm{GPa}$, below the crystallization pressure of the reaction product observed by XRD, the extra band at $4123 \mathrm{~cm}^{-1}$ disappears, while the bands of $\mathrm{PH}_{3}$ exhibit a high-frequency shift (Supplementary Fig. 5) and those of $\mathrm{H}_{2}$ a low-frequency shift. Both $\mathrm{PH}_{3}$ and $\mathrm{H}_{2}$ bands frequencies all undergo a low-frequency shift on further decompression and disappear after opening the cell.

At $1.95 \mathrm{GPa}$ three sharp bands, unambiguously identified as the characteristic $A_{\mathrm{g}}^{(1)}, E_{\mathrm{g}}$ and $A_{\mathrm{g}}^{(2)}$ signatures of $P_{\text {black }}$, respectively appear at 373,443 , and $467 \mathrm{~cm}^{-1}$, remaining observable on decompression down to ambient pressure (Supplementary Fig. 5). Even if the detection of these three peaks could suggest an incomplete transformation of $P_{\text {black }}$ and its missed observation, the 
Table 1 Infrared absorption frequencies at different pressure values.

\begin{tabular}{|c|c|c|c|c|c|c|c|}
\hline IR bands & $6.7(\mathrm{GPa})$ & $3.1(\mathrm{GPa})$ & $1.9(\mathrm{GPa})$ & 0 (GPa) & $\operatorname{gas}^{52}$ & Liquid52 & solid $(35 \mathrm{~K})^{51}$ \\
\hline $\mathrm{PH}_{3} \nu_{2}\left(A_{1}\right)$ bend-s & 983 & 1005 & 1002 & & 992 & $\sim 1100$ & 980.3 \\
\hline $\mathrm{PH}_{3} \nu_{4}(E)$ bend-as & $\sim 1100^{a}$ & & & & 1122 & $\sim 1100$ & 1095.4 \\
\hline \multirow[t]{2}{*}{$\mathrm{PH}_{3} \nu_{1}\left(A_{1}\right)$ str-s, $\nu_{3}(E)$ str-s } & 2358 & 2365 & $\sim 2350^{a}$ & & $2321\left(\nu_{1}\right)$ & 2314 & $2303.6\left(\nu_{1}\right)$ \\
\hline & 3346 & & & & $2327\left(\nu_{3}\right)$ & & $2311.3\left(\nu_{3}\right)$ \\
\hline $\mathrm{PH}_{3}\left(\nu_{1}+\nu_{4}\right):\left(\nu_{3}+\nu_{4}\right)$ & $\begin{array}{l}3466 \\
4121\end{array}$ & 3472 & 3458 & & & 3402 & \\
\hline $\mathrm{H}_{2}\left(\mathrm{Q}_{1}(1)\right)$ & 4250 & 4184 & 4173 & & & & \\
\hline $\mathrm{H}_{2}\left(\mathrm{Q}_{1}(1)+\mathrm{S}_{0}(0)\right)$ & 4625 & & & & & & \\
\hline $\mathrm{H}_{2}\left(\mathrm{Q}_{1}(1)+\mathrm{S}_{0}(1)\right)$ & 4814 & & & & & & \\
\hline
\end{tabular}

Infrared absorption frequencies acquired at different pressure values during decompression to ambient pressure. The peak position of the $\nu_{4}$ band is not observable due to the overlap with the saturating absorption of the la diamond anvils. $\nu_{1}$ and $\nu_{3}$ are overlapped and unresolved. Literature values for $\mathrm{PH}_{3}$ are also reported.

bend bending, str stretching, -s symmetric, -as asymmetric.

aOut of scale absorption.

Raman spectra acquired at $0.2 \mathrm{GPa}$ and at ambient pressure on the recovered sample show characteristic bands at $\sim 385 \mathrm{~cm}^{-1}$, which is not present in any of the $P_{\text {red }}$ forms nor in $P_{\text {black }}$ (Supplementary Fig. 7), and at $2245 \mathrm{~cm}^{-1}$ in the $\mathrm{P}-\mathrm{H}$ stretching region, which closely resemble the Raman spectra reported by Yuan and coauthors for the recovered products of the decomposition of $\mathrm{PH}_{3}$ quenched from $25 \mathrm{GPa}$ to $31 \mathrm{GPa}^{55}$ (Supplementary Fig. 8), thus suggesting a laser-induced decomposition of $\mathrm{PH}_{3}$ during the acquisition of the Raman spectra, after releasing pressure below the crystallization threshold of the reaction product.

Interestingly, the P-H stretching band observed at $2200 \mathrm{~cm}^{-1}$ at $6.8 \mathrm{GPa}$ exhibits a high-frequency shift to $\sim 2226 \mathrm{~cm}^{-1}$ on releasing pressure to $3.1 \mathrm{GPa}$, which further increases to $2245 \mathrm{~cm}^{-1}$ on releasing pressure to ambient conditions (Supplementary Fig. 5), providing evidence of the presence of $\mathrm{H}$-bonding in the recovered solid product. Unfortunately, no additional insight could be gained on the recovered solid material responsible for type-1 Raman spectrum, which appears to consists of a hydrogenated $(\mathrm{H}$ functionalized) mixture of amorphous $P_{\text {red }}$ and crystalline $P_{\text {black. }}$

\section{Discussion}

Our data provide clear experimental evidence for direct highpressure and high-temperature chemical reactivity between elemental $\mathrm{P}_{\text {black }}$ and $\mathrm{H}_{2}$. The resulting formation of $\mathrm{PH}_{3}$ according to the following chemical equation

$$
\mathrm{P}+\frac{3}{2} \mathrm{H}_{2} \stackrel{1.2 \mathrm{GPa}, 1000 \mathrm{~K}}{\underset{\text { no catalyst }}{\longrightarrow}} \mathrm{PH}_{3}
$$

represents the so far unreported catalyst-free phosphorus analogue of the nitrogen-based Haber-Bosch reaction for the synthesis of $\mathrm{NH}_{3}$ (Supplementary Note 9).

Compressing $\mathrm{PH}_{3}$ in excess $\mathrm{H}_{2}$ at room $\mathrm{T}$, between 3.5 and 4.1 GPa, the XRD data indicate the crystallization of a reaction product. As type-1 Raman spectrum was assigned to an amorphous solid product, we related the X-ray diffraction pattern of our crystalline product to type-2 Raman spectra, in which $\mathrm{PH}_{3}$ is observed, and considered the $\mathrm{P}$ positions of the corresponding structure to be occupied by $\mathrm{PH}_{3}$ molecules. The presence of $\mathrm{PH}_{3}$ in type-2 Raman spectra is always associated to the detection of an extra band in the $\mathrm{H}_{2}$ stretching region at lower frequency compared to pure $\mathrm{H}_{2}$, which disappears on releasing pressure below the crystallization threshold of the crystalline reaction product. A similar behavior is observed in the IR spectra, where an extra band is detected at $4121 \mathrm{~cm}^{-1}$ $(6.7 \mathrm{GPa})$, almost exactly coinciding with the frequency of the extra Raman band at $4123 \mathrm{~cm}^{-1}(6.8 \mathrm{GPa})$.

Whereas the sharp higher frequency band perfectly matches with the literature data about $\mathrm{H}_{2}$ molecules in crystalline phase I $\left(4250 \mathrm{~cm}^{-1} \text { in IR and } 4212 \mathrm{~cm}^{-1} \text { in Raman at } 6.8 \mathrm{GPa}\right)^{56}$, the unassigned and unexpected broader extra band at lower frequency $\left(4121 \mathrm{~cm}^{-1}\right.$ at $6.7 \mathrm{GPa}$ in IR and $4123 \mathrm{~cm}^{-1}$ at $6.8 \mathrm{GPa}$ in Raman), indicates the presence of a second type of $\mathrm{H}_{2}$ molecules, which experience a significant weakening of the bond force constant (5.15\%, average value between $4.30 \%$ Raman and $6.00 \%$ IR weakening), likely due to a different local force field, as indeed consistently attested by their larger bandwidth in comparison to pure $\mathrm{H}_{2}$.

A possible interpretation for this occurrence is the formation of a van der Waals crystalline compound made of $\mathrm{PH}_{3}$ and $\mathrm{H}_{2}$ molecules with $\left(\mathrm{PH}_{3}\right)_{2} \mathrm{H}_{2}$ stoichiometry and a tetragonal $\mathrm{Al}_{2} \mathrm{Cu}$ like structure belonging to $I 4 \mathrm{~cm}$ space group ${ }^{26}$, where $\mathrm{PH}_{3}$ and $\mathrm{H}_{2}$ respectively occupy $8 c\left(C_{s}\right)$ and $4 a\left(C_{4}\right)$ Wyckoff sites (Fig. 4). In this structure four molecules of $\mathrm{PH}_{3}$ are located on a plane parallel to the $[\mathrm{a}, \mathrm{b}]$ direction at $0.5 \mathrm{z}$ and occupy the positions around a 4 -fold rotation axis $\left(C_{4}\right)$ along the $c$ direction. Four additional molecules occupy the positions generated by a rotation along $C_{4}$ and a translation along $+0.5 \mathrm{z}$, giving rise to alternatively rotated layers of $\mathrm{PH}_{3}$ molecules.

This interpretation of our data is in agreement with the $14 \mathrm{~cm}$ tetragonal structure of $\mathrm{P}$ atoms obtained from the single-crystal data and also accounts for the existence of free volume in the unit cell, in the case $\mathrm{PH}_{3}$ only would be present.

Furthermore, in this structure the $\mathrm{H}_{2}$ molecules are encaged within square antiprismatic voids delimited by eight $\mathrm{PH}_{3}$ molecules (four on one layer and four on the adjacent layer) and occupy a single type of crystal site $\left(C_{4}\right)$, corresponding to $4 a$ Wyckoff positions, whose occupancy, according to group theory, is consistent with the appearance of one infrared and Raman active crystal component for the $\mathrm{H}_{2}$ stretching vibration (Supplementary Note 6 and Supplementary Fig. 10).

In addition, the occupation by $\mathrm{PH}_{3}$ molecules of $8 c$ Wyckoff sites $\left(C_{s}\right)$, is consistent with the splitting of the $\left(v_{1}+v_{4}\right) ;\left(v_{3}+v_{4}\right)$ combination band. The extra band observed in the IR spectra at $3346 \mathrm{~cm}^{-1}$ at $6.8 \mathrm{GPa}$, disappearing on decompression to 3.1 GPa, can be thus assigned to $\mathrm{PH}_{3}$ molecules forming the $\left(\mathrm{PH}_{3}\right)_{2} \mathrm{H}_{2}$ crystal structure (Supplementary Note 6 and Supplementary Fig. 10).

A density of $1.269 \mathrm{~g} \mathrm{~cm}^{-3}$ can be calculated at $5.5 \mathrm{GPa}$ from the refinement of the single-crystal data, with $2.89 \%$ in weight of $\mathrm{H}_{2}$ and total $11.5 \%$ in weight of $\mathrm{H}\left(\mathrm{H}_{2}+\mathrm{H}\right.$ in $\left.\mathrm{PH}_{3}\right)$.

The molecular nature of the reaction product is further confirmed by the bulk modulus $B=6.7 \pm 0.8 \mathrm{GPa}$ derived from the 2nd order Birch-Murnaghan equation of state in the investigated pressure range, which is in absolute agreement with analogous systems ${ }^{26}$, and by the pressure evolution of the nearly constant $c / a$ axial ratio, which indicates an almost isotropic compression within the applied pressure range (Supplementary Note 7). 
a

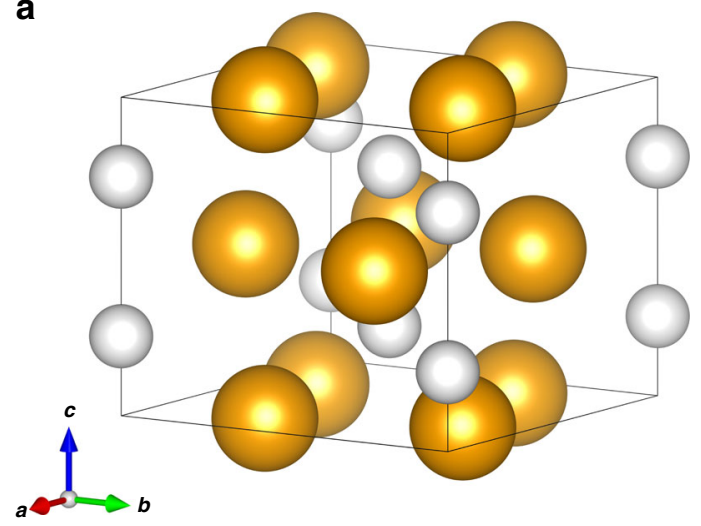

C

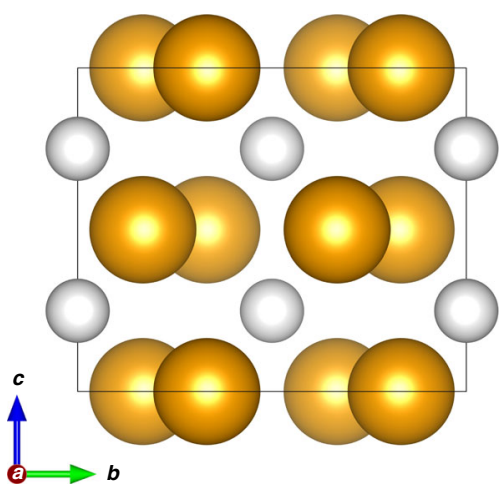

b

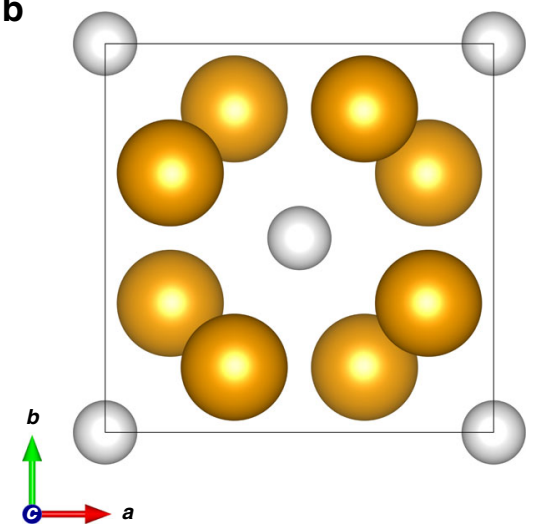

d

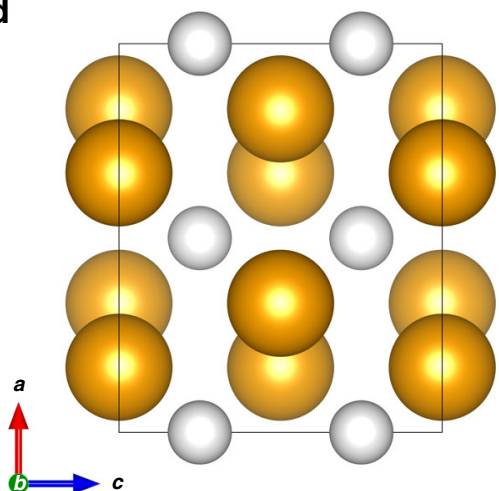

Fig. 4 Crystal structure of the $\left(\mathbf{P H}_{\mathbf{3}} \mathbf{~}_{\mathbf{2}} \mathbf{H}_{\mathbf{2}} \mathbf{v d W}\right.$ compound. Crystal structure of the $\left(\mathrm{PH}_{3}\right)_{2} \mathrm{H}_{2}$ vdW compound at $5.5 \mathrm{GPa}$ and room $\mathrm{T}$ (a) with views along the $c(\mathbf{b}), a(\mathbf{c})$, and $b(\mathbf{d})$ crystal axes. The orange spheres represent the $\mathrm{PH}_{3}$ molecules, whereas the white spheres represent the $\mathrm{H}_{2}$ molecules. The size of the spheres has been drawn by estimating their radius as the sum of the $\mathrm{P}-\mathrm{H}$ bond length $(1.421 \AA)^{2}$ and $\mathrm{H}$ van der Waals radius $(1.20 \AA)^{49}$ in the case of $\mathrm{PH}_{3}(2.62 \AA)$ and as the sum of the $\mathrm{H}$ van der Waals radius $(1.20 \AA)^{49}$ and half of the $\mathrm{H}-\mathrm{H}$ distance $(0.742 \AA)^{74}$ in the case of $\mathrm{H}_{2}(1.571 \AA)$.

Pressure has greatly extended the number of known hydrides synthesized under high-density conditions ${ }^{15,33}$. Among non metallic elements, $\mathrm{H}_{2}$-containing hydrides have been reported so far in literature for elements ranging from group 14 to group 18 of the periodic table, and include van der Waals hydrides of noble gases, simple diatomic molecules, and covalent molecular hydrides (Supplementary Fig. 16).

If among these hydrides we only consider those involving elements which are able to form covalent molecular hydrides (Supplementary Fig. 17) and particularly focus on those which have been reported to adopt a $I 4 \mathrm{~cm}(I 4 / \mathrm{mcm})$ crystal structure with $\mathrm{X}_{2} \mathrm{H}_{2}$ composition, where $\mathrm{X}$ represents the corresponding molecular hydride (Supplementary Fig. 18), then we observe that this structure has been experimentally reported in the case of: carbon, with methane $\left(\mathrm{CH}_{4}\right)^{19}$, for group 14; sulphur, with $\mathrm{H}_{2} \mathrm{~S}^{26}$, and selenium, with $\mathrm{H}_{2} \mathrm{Se}^{27}$, for group 16; and iodine, with $\mathrm{HI}^{57}$, for group 17. Interestingly, to the best of our knowledge no such structure has been reported so far for any of the elements of group 15 .

In particular $\left(\mathrm{CH}_{4}\right)_{2} \mathrm{H}_{2},\left(\mathrm{H}_{2} \mathrm{~S}\right)_{2} \mathrm{H}_{2},\left(\mathrm{H}_{2} \mathrm{Se}\right)_{2} \mathrm{H}_{2}$ and $(\mathrm{HI})_{2} \mathrm{H}_{2}$ all reportedly exhibit the same $I 4 / \mathrm{mcm}$ structure, with the $\mathrm{H}_{2}$ and $\mathrm{X}$ molecules respectively occupying $4 a$ and $8 h$ Wyckoff positions, whereas $\left(\mathrm{PH}_{3}\right)_{2} \mathrm{H}_{2}$ exhibits a $\mathrm{I} 4 \mathrm{~cm}$ structure with the $\mathrm{H}_{2}$ and $\mathrm{PH}_{3}$ molecules occupying the $4 a$ and $8 c$ Wyckoff positions. The $14 \mathrm{~cm}$ and $I 4 / \mathrm{mcm}$ structures are closely related and only differ for the presence of an inversion center in $14 / \mathrm{mcm}$, with identical lattice parameters and atomic positions. Noticeably, even if the occupation of $8 h$ Wyckoff positions of $\mathrm{C}_{2 \mathrm{v}}$ site symmetry by $\mathrm{CH}_{4}, \mathrm{H}_{2} \mathrm{~S}, \mathrm{H}_{2} \mathrm{Se}$ and $\mathrm{HI}$, respectively in $\left(\mathrm{CH}_{4}\right)_{2} \mathrm{H}_{2},\left(\mathrm{H}_{2} \mathrm{~S}\right)_{2} \mathrm{H}_{2},\left(\mathrm{H}_{2} \mathrm{Se}\right)_{2} \mathrm{H}_{2}$ and
$(\mathrm{HI})_{2} \mathrm{H}_{2}$ does not rise any symmetry issue (such as in the case of $\mathrm{PH}_{3}\left(C_{3 \mathrm{v}}\right)$ occupying a $C_{2 \mathrm{v}}$ site in the $\mathrm{I} / \mathrm{mcm}$ structure), no infrared spectra for any of these compounds have been acquired in the $\mathrm{H}_{2}$ stretching region, where, according to the analysis of the Davydov components activity using group theory arguments, the appearance of an extra band would unambiguously support the formation of a structure belonging to the $14 \mathrm{~cm}$ rather than to the $I 4 / \mathrm{mcm}$ space group (Supplementary Note 6). Indeed, the possibility of the $I 4 \mathrm{~cm}$ lower symmetry structure has been proposed also for $\left(\mathrm{H}_{2} \mathrm{~S}\right)_{2} \mathrm{H}_{2}{ }^{26}$, whereas the $I 4 / \mathrm{mcm}$ structures of $\left(\mathrm{H}_{2} \mathrm{Se}\right)_{2} \mathrm{H}_{2}$ and $(\mathrm{HI})_{2} \mathrm{H}_{2}$ were assigned according to similarity with $\left(\mathrm{H}_{2} \mathrm{~S}\right)_{2} \mathrm{H}_{2}$, thus suggesting all these structures to belong to $I 4 \mathrm{~cm}$ rather than $I 4 / \mathrm{mcm}$ space group. Furthermore, the consistency of the IR and Raman optical activity with the application of group theory to the crystal symmetry, indicates that the $\mathrm{PH}_{3}$ molecules are not randomly oriented and that their orientations reflect the symmetry and periodicity of the intermolecular potential originating from their symmetry. This apparently contrasts with the orientational disorder reported for $\mathrm{CH}_{4}, \mathrm{H}_{2} \mathrm{~S}, \mathrm{H}_{2} \mathrm{Se}$, and $\mathrm{HI}$, respectively, in $\left(\mathrm{CH}_{4}\right)_{2} \mathrm{H}_{2},\left(\mathrm{H}_{2} \mathrm{~S}\right)_{2} \mathrm{H}_{2}$, $\left(\mathrm{H}_{2} \mathrm{Se}\right)_{2} \mathrm{H}_{2}$, and $(\mathrm{HI})_{2} \mathrm{H}_{2}$, which has been speculated from the behavior of the pure hydrides, without any conclusive evidence to support it like IR absorption spectra in the $\mathrm{H}_{2}$ stretching region (Supplementary Note 10$)^{58,59}$.

The identification of $\left(\mathrm{PH}_{3}\right)_{2} \mathrm{H}_{2}$ thus represents the discovery of the missing tile for group 15, specifically corresponding to phosphorus, in the puzzle of the periodic properties of nonmetallic elements, which are able to form van der Waals molecular compounds containing their covalent hydrides and $\mathrm{H}_{2}$ molecules (Fig. 5). 


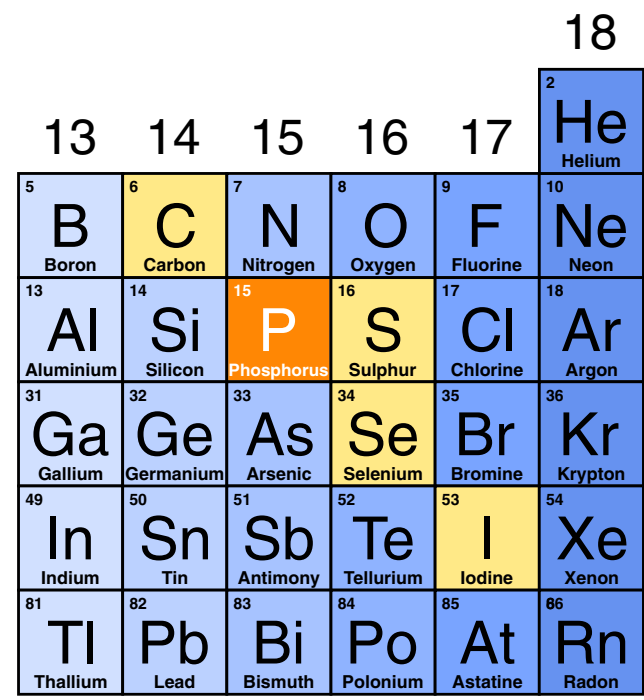

Fig. 5 The missing tile of $\mathbf{P}$ for group 15. Non-metal region of the Periodic Table showing the elements (yellow and orange) able to form crystalline $\mathrm{X}_{2} \mathrm{H}_{2}$ vdW compounds $\left(\mathrm{X}=\mathrm{CH}_{4}{ }^{19}, \mathrm{PH}_{3}, \mathrm{H}_{2} \mathrm{~S}^{26}, \mathrm{H}_{2} \mathrm{Se}^{27}, \mathrm{HI}^{57}\right.$ ) having the $14 \mathrm{~cm}(14 / \mathrm{mcm})$ structure, with $\mathrm{P}\left(\mathrm{X}=\mathrm{PH}_{3}\right)$, highlighted in orange, representing the so far missing tile for group 15 elements reported in this study (see text).

\begin{tabular}{|l|c|c|c|r|}
\hline Hydride & $\mathrm{P}(\mathrm{GPa})$ & $v_{\mathrm{H}_{2}}\left(\mathrm{X}_{2} \mathrm{H}_{2}\right)$ & $v_{\mathrm{H}_{2}}\left(\mathrm{H}_{2}\right)$ & $\Delta v$ \\
\hline $\mathrm{CH}_{4}$ & 5.4 & - & - & +13 \\
$\mathrm{PH}_{3}$ & 6.8 & 4121 & 4213 & -92 \\
$\mathrm{H}_{2} \mathrm{~S}$ & 7.0 & 4147 & 4213 & -66 \\
$\mathrm{H}_{2} \mathrm{Se}$ & 7.0 & 4106 & 4213 & -107 \\
$\mathrm{HI}$ & 6.8 & 4162 & 4213 & -51 \\
\hline \hline
\end{tabular}

$\left.\right|_{\mathrm{H}} ^{\mathrm{C}}{ }_{\mathrm{H}}^{\mathrm{C}} \mathrm{H}_{\mathrm{H}}$

Fig. 6 Raman shift of the $\mathrm{H}_{2}$ stretching vibration in different isostructural $\mathbf{X}_{\mathbf{2}} \mathbf{H}_{\mathbf{2}}$ compounds. Upper panel. Table reporting the Raman frequency $\left(\mathrm{cm}^{-1}\right)$ of the $\mathrm{H}-\mathrm{H}$ stretching vibration of $\mathrm{H}_{2}$ molecules in different isostructural $\mathrm{X}_{2} \mathrm{H}_{2}$ crystals $\left(\nu_{\mathrm{H}_{2}}\left(\mathrm{X}_{2} \mathrm{H}_{2}\right)\right.$ with $\mathrm{X}=\mathrm{CH}_{4}{ }^{19}, \mathrm{PH}_{3}, \mathrm{H}_{2} \mathrm{~S}^{26}, \mathrm{H}_{2} \mathrm{Se}^{27}$, and $\left.\mathrm{HI}^{57}\right)$ and their frequency shift $(\Delta \nu)$ with respect to bulk $\mathrm{H}_{2}\left(\nu_{\mathrm{H}_{2}}\left(\mathrm{H}_{2}\right)\right)$ in comparable pressure conditions. Ref. ${ }^{19}$ directly provides the frequency shift value for $\mathrm{CH}_{4}$. Lower panel. The molecular structures of $\mathrm{CH}_{4}, \mathrm{PH}_{3}, \mathrm{H}_{2} \mathrm{~S}, \mathrm{H}_{2} \mathrm{Se}$, and $\mathrm{HI}$, drawn according to the VSEPR theory and fulfilling the octet rule for the electron outer shell, are shown to highlight the absence of lone pairs on $\mathrm{C}$ in $\mathrm{CH}_{4}$, comparing to the other hydride forming elements.

A further chemical insight can be gained from the Raman data. All these five $\mathrm{X}_{2} \mathrm{H}_{2}$ isostructural compounds feature the extra Raman band in the $\mathrm{H}_{2}$ stretching region, due to the vibration of the $\mathrm{H}_{2}$ molecules inside their structure, in addition to the signal of the surrounding pure $\mathrm{H}_{2}$, which is always present as excess reactant from the synthesis. These frequencies are listed in the Table in Fig. 6, together with the corresponding frequency shift with respect to pure $\mathrm{H}_{2}$. An interesting feature emerging from this comparison is that, at similar high-pressure conditions, the frequency shift of the extra band with respect to pure $\mathrm{H}_{2}$ is always negative, except in the case of methane. According to the valence shell electron pair repulsion (VSEPR) theory, and to the fulfillment of the octet rule for the outer electronic shell ${ }^{45}$, the main difference between methane and the other hydrides is that methane does not possess an electron lone pair on carbon, whereas $\mathrm{PH}_{3}, \mathrm{H}_{2} \mathrm{~S}, \mathrm{H}_{2} \mathrm{Se}$ and $\mathrm{HI}$ all have at least one electron lone pair on the hydride forming element (Fig. 6).

The presence of lone pairs is typically associated to the ability of forming $\mathrm{H}$-bonding, as indeed observed for all these systems, and of behaving as an electron donor Lewis base. H-bonding between the corresponding hydride molecules, evidenced by a negative frequency shift with increasing pressure of the internal stretching modes involving $\mathrm{H}$ atoms, has been indeed reported for $\left(\mathrm{H}_{2} \mathrm{~S}\right)_{2} \mathrm{H}_{2},\left(\mathrm{H}_{2} \mathrm{Se}\right)_{2} \mathrm{H}_{2}$, and $(\mathrm{HI})_{2} \mathrm{H}_{2}$.

The high-frequency shift, observed both in the infrared and Raman spectra acquired on releasing pressure from 6.8 to $3.1 \mathrm{GPa}$ across the melting threshold of the crystalline product (Supplementary Fig. 6), suggests also $\mathrm{PH}_{3}$ to behave like the analogous $\mathrm{X}_{2} \mathrm{H}_{2}$ isostructural van der Waals compounds, exhibiting $\mathrm{H}_{3} \mathrm{P} \quad \cdots \quad \mathrm{H}-\mathrm{PH}_{2}$ H-bonding interactions, which disappear on decompression from 6.8 to $3.1 \mathrm{GPa}$ after the decomposition of $\left(\mathrm{PH}_{3}\right)_{2} \mathrm{H}_{2}$, as attested by the decrease of the vibrational frequencies of $\mathrm{PH}_{3}$ on further decompression.

The presence of a $\mathrm{H}$-bonding between $\mathrm{PH}_{3}$ molecules has noticeable chemical relevance as $\mathrm{PH}_{3}$, in contrast to $\mathrm{NH}_{3}$, is known for not forming $\mathrm{H}$-bonding at ambient conditions ${ }^{45,46}$, due to the small electronegativity difference of phosphorus with respect to hydrogen and to the consequent smaller electric dipole moment ${ }^{60}$. Furthermore, the existence of such interaction, together with the presence of $\mathrm{H}_{2}$ molecules, is in agreement with the larger volume of the crystalline cell of $\left(\mathrm{PH}_{3}\right)_{2} \mathrm{H}_{2}$ compared to what expected in pure $\mathrm{PH}_{3}$.

The softening of the stretching vibration in the $\mathrm{H}_{2}$ molecules forming the $\left(\mathrm{PH}_{3}\right)_{2} \mathrm{H}_{2}$ crystal clearly indicates the presence of chemical interaction between $\mathrm{H}_{2}$ and $\mathrm{PH}_{3}$. In the case of the isolated molecules such interaction has been described by ab initio computational methods ${ }^{61}$ in terms of two possible contributions: 1) the electron lone pair of $\mathrm{P}$ can act as a Lewis base and the $\sigma^{*}$ anti-bonding molecular orbital of $\mathrm{H}_{2}$ as a Lewis acid $\left(n \rightarrow \sigma^{*}\right) ; 2$ ) the $\sigma$ bonding molecular orbital electrons of $\mathrm{H}_{2}$ act as Lewis base and the first anti-bonding molecular orbital of $\mathrm{PH}_{3}$ as a Lewis acid $\left(\sigma \rightarrow \sigma^{*}\left(\mathrm{H}-\mathrm{PH}_{2}\right)\right)$.

The first interaction is essentially a HOMO-LUMO orbital overlap interaction involving the highest occupied molecular orbital (HOMO) of $\mathrm{PH}_{3}\left(2 a_{1}\right.$ symmetry), which hosts the electron lone pair and has a prevalent non-bonding character, and the unoccupied $\sigma^{*}$ anti-bonding molecular orbital of $\mathrm{H}_{2}$, technically the lowest unoccupied molecular orbital (LUMO), whereas the second one corresponds to the opposite situation, where the HOMO $\sigma$ bond electron density of $\mathrm{H}_{2}$ interacts with the LUMO orbital of $\mathrm{PH}_{3}\left(3 a_{1}\right)$ (Fig. 7). Energetically, the first interaction is larger when the $2 a_{1}$ HOMO of $\mathrm{PH}_{3}$ and the $\sigma^{*}$ of $\mathrm{H}_{2}$ have maximum overlap, with the electron lone pair and the molecular axis of $\mathrm{H}_{2}$ aligned, but is present, even to a smaller extent, also in other interaction configurations, whereas the second one requires the $\sigma$ electron density of $\mathrm{H}_{2}$ to interact with the $3 a_{1}$ LUMO of $\mathrm{PH}_{3}$ in a configuration where the electron lone pair is perpendicular to $\mathrm{H}_{2}$ molecular axis.

In solid state, as group 15 elements are concerned, the first kind of interaction has been recently reported to be responsible for the softening of the $\mathrm{H}_{2}$ stretching vibration in the $\mathrm{As}_{4} \mathrm{O}_{6} \cdot 2 \mathrm{H}_{2}$ crystal by electron density transfer from the As electron lone pair to the $\sigma^{*}$ anti-bonding orbital of $\mathrm{H}_{2}{ }^{62}$. Gúnka et al. achieved this result by adopting the ICOHP (integrated projected crystal orbital Hamilton population) and ICOOP (integrated projected crystal orbital overlap population) computational methods, which, based on the crystal orbital overlap population (COOP) approach originally developed by $\mathrm{R}$. Hoffmann ${ }^{63}$, indeed relate the local molecular orbitals to the band structure of crystals through the projection decomposition of the electron density of states, 
a<smiles>C</smiles>
Molecular orbital diagram for pyramidal $\mathrm{AH}_{3}$
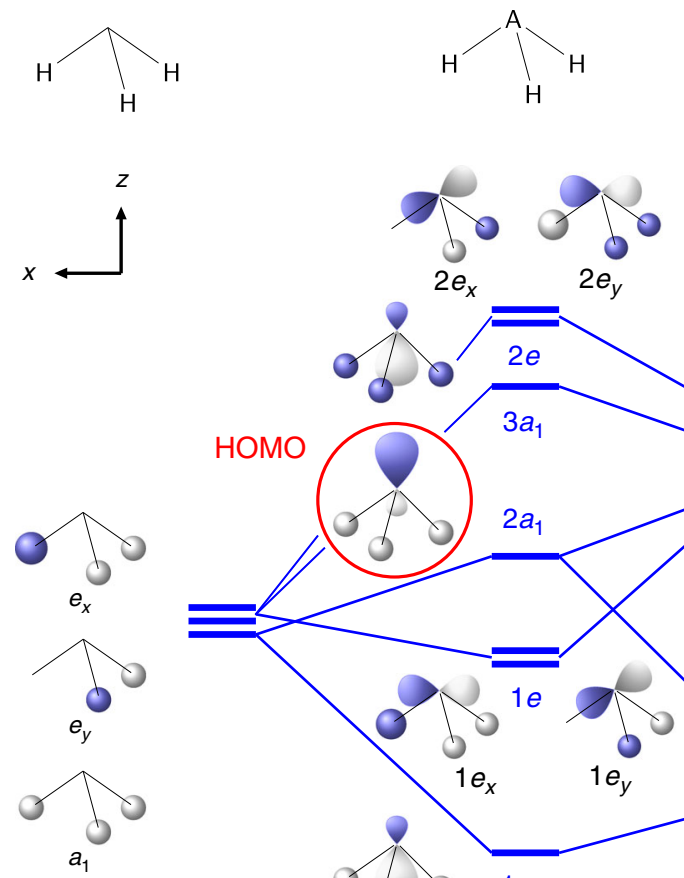

西

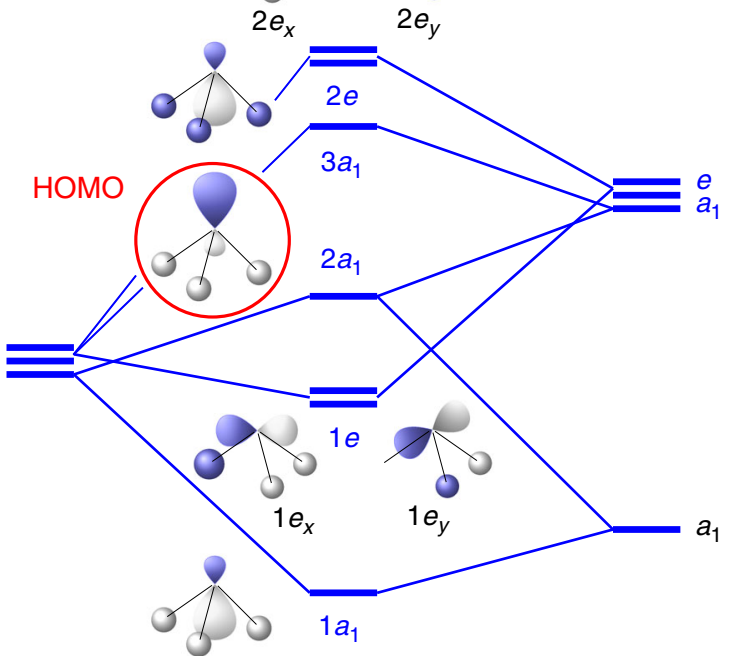

A

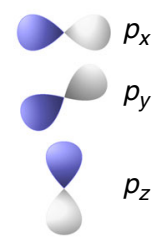

b

Molecular orbital diagram for $\mathrm{H}_{2}$

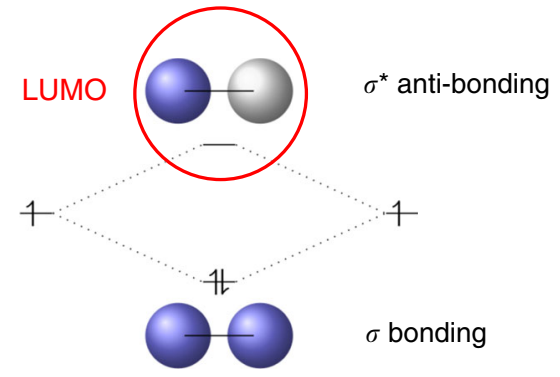

C

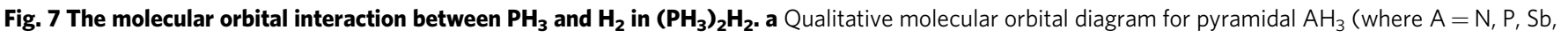

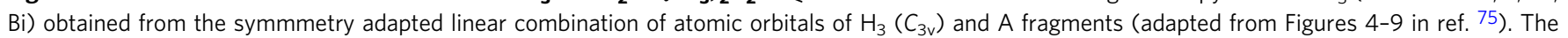

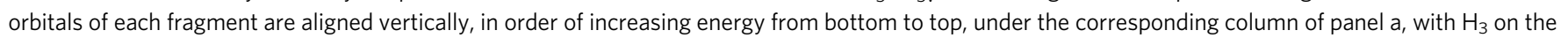
left side, $\mathrm{AH}_{3}$ in the middle and $\mathrm{A}$ on the right side. The $2 a_{1}$ highest occupied molecular orbital (HOMO), where the electron lone pair is located, is

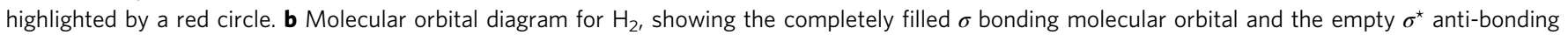

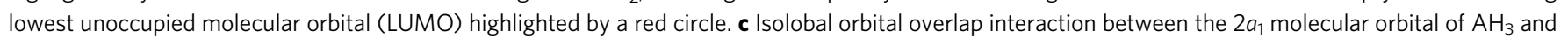
the $\sigma^{\star}$ anti-bonding molecular orbital of $\mathrm{H}_{2}$.

allowing to gain insight about the frontier orbitals that control structure and reactivity in extended systems.

Accordingly, a qualitative interpretation for the softening of the stretching vibration of the $\mathrm{H}_{2}$ molecules in the $\left(\mathrm{PH}_{3}\right)_{2} \mathrm{H}_{2}$ crystal, certainly deserving appropriate theoretical investigation for effective electronic band structure calculation, is here proposed in terms of isolobal frontier molecular orbital overlap interaction between the HOMO of $\mathrm{PH}_{3}$, hosting the electron lone pair, and the $\sigma^{*}$ anti-bonding LUMO of $\mathrm{H}_{2}$ (Fig. 7). Even if the orientation of $\mathrm{PH}_{3}$ and $\mathrm{H}_{2}$ molecules is not known, considering that $\mathrm{H}_{2}$ is expected to undergo hindered rotations at this pressure, it is indeed likely that the $2 a_{1} \mathrm{HOMO}$ of some of the $\mathrm{PH}_{3}$ molecules building up the cavities, where the $\mathrm{H}_{2}$ molecules are hosted, and the $\sigma^{*}$ anti-bonding orbital of $\mathrm{H}_{2}$ dynamically adopt the correct orientation for an effective overlap. The $\sigma^{*}$ anti-bonding orbital of $\mathrm{H}_{2}$ is normally not occupied, which makes the $\mathrm{H}_{2}$ molecule stable. The electron density transfer from the lone pair of $\mathrm{PH}_{3}$ to the $\sigma^{*}$ anti-bonding orbital of $\mathrm{H}_{2}$ may decrease the bonding electron density of the $\mathrm{H}_{2}$ molecule, thus causing a reduction of the force constant $(\sim 5.15 \%)$ and finally a frequency decrease of the $\mathrm{H}_{2}$ stretching mode, according to the harmonic oscillator frequency equation $\left(v=\frac{1}{2 \pi} \sqrt{\frac{k}{\mu}}\right)$. The existence of the $\sigma\left(\mathrm{H}_{2}\right) \rightarrow \sigma^{*}\left(\mathrm{H}-\mathrm{PH}_{2}\right)$ interaction may further contribute to this effect. As a result, the $\mathrm{H}_{2}$ molecules within the crystal structures of $\left(\mathrm{PH}_{3}\right)_{2} \mathrm{H}_{2}$ exhibit a lower vibrational frequency compared to bulk solid $\mathrm{H}_{2}$.

Finally, the observation of $\left(\mathrm{PH}_{3}\right)_{2} \mathrm{H}_{2}$ is also somehow relevant for superconductivity in $\mathrm{PH}_{3} . \mathrm{PH}_{3}$ has been experimentally reported to become metallic at $40 \mathrm{GPa}$ and superconducting at
$207 \mathrm{GPa}$ with a $\mathrm{T}_{\mathrm{c}}$ of $103 \mathrm{~K}$, but with no structural characterization so $\mathrm{far}^{36}$. Since then quite a lot of theoretical efforts have been made to account for such observation. At the moment, theory and experiments seem to agree about the instability of pure $\mathrm{PH}_{3}$ at high pressure, whose decomposition proceeds through the release of $\mathrm{H}_{2}$. Experimentally, a couple of recent papers have reported the decomposition of $\mathrm{PH}_{3}{ }^{55,64}$, with the initial formation of diphosphane followed by decomposition into elemental phosphorus and $\mathrm{H}_{2}$. However, no further convincing characterization was proposed, suggesting that, like in the case of $\mathrm{H}_{2} \mathrm{~S}$, other species may be responsible for the superconductivity observed by Drozdov et al. ${ }^{36}$. Theoretically, besides predicting the decomposition of $\mathrm{PH}_{3}$, different studies have calculated the stabilization of $\mathrm{PH}_{2}$ phases above $80 \mathrm{GPa}$, which, from a stoichiometric point of view, is consistent with the release of $\mathrm{H}_{2}{ }^{37,38}$. Furthermore, a key role of molecular $\mathrm{H}_{2}$ in stabilizing the highpressure superconducting phases of phosphorus hydrides has been recently proposed ${ }^{39}$. Interestingly, even if the pressure range is here much lower, our data show that $\mathrm{PH}_{3}$ and $\mathrm{H}_{2}$ form a crystalline vdW compound, in which molecular $\mathrm{H}_{2}$ is indeed involved, possibly stabilizing $\mathrm{PH}_{3}$, or other related species, even at higher pressure.

To summarize, the results of this study have multiple chemically relevant implications. First of all, using $\mathrm{LH}$ in DAC, we have successfully induced direct reactivity between $\mathrm{P}_{\text {black }}$ and $\mathrm{H}_{2}$ at 1.2 $\mathrm{GPa}$ and temperature lower than $1000 \mathrm{~K}$, without the use of any catalyst or precursor. To our knowledge this is the first report about a direct chemical reaction between $\mathrm{P}_{\text {black, }}$ the thermodynamically stable allotrope of $\mathrm{P}$, and $\mathrm{H}_{2}$ at high pressure and 
high temperature to form $\mathrm{PH}_{3}$, somehow mimicking and representing the $\mathrm{P}$ analogue of the Haber-Bosch process for the synthesis of $\mathrm{NH}_{3}$ from $\mathrm{N}_{2}$ and $\mathrm{H}_{2}$.

Secondly, at room $\mathrm{T}$ and pressure between 3.5 and $4.1 \mathrm{GPa} \mathrm{PH}_{3}$ combines with excess $\mathrm{H}_{2}$ to form the crystalline $\left(\mathrm{PH}_{3}\right)_{2} \mathrm{H}_{2}$ van der Waals compound, whose observation consistently fills a gap existing for pnictogens in the periodic properties of non-metallic elements able to form crystalline vdW compounds made of the corresponding hydride and of molecular hydrogen. The identification of $\left(\mathrm{PH}_{3}\right)_{2} \mathrm{H}_{2}$ represents the so far missing tile of $\mathrm{P}$ in this puzzle and confirms a general trend in the formation of $\mathrm{H}_{2}$ containing vdW compounds with $\mathrm{X}_{2} \mathrm{H}_{2}$ stoichiometry $(\mathrm{X}=$ molecular hydride) and $I 4 \mathrm{~cm}(I 4 / \mathrm{mcm})$ structure.

The formation of unexpected chemical compounds made of components apparently non-interacting at ambient conditions, such as $\mathrm{P}$ and $\mathrm{H}$, is extremely important for their relevant implications, which include $\mathrm{H}_{2}$ storage, the chemistry occurring in extraterrestrial environments of giant planets such as Jupiter, Saturn, and their moons, where $\mathrm{PH}_{3}$ and $\mathrm{H}_{2}$ are present ${ }^{40,41,43}$, and the identification of astrochemical processes leading to the synthesis of phosphine, which is a critical issue for the detection of the presence of life in harsh extraterrestrial environments of rocky planets, as inferred by the recent observation of anomalous high levels of phosphine in the cloud decks of Venus atmosphere $^{65}$.

Third, as advancement in fundamental bond theory is concerned, the relevant observation of $\mathrm{H}$-bonding in $\mathrm{PH}_{3}$, which in contrast to $\mathrm{NH}_{3}$ is not reported to exist at ambient pressure, and the existence of a molecular orbital interaction between the electron lone pair in $\mathrm{PH}_{3}$ and the antibonding molecular orbital of $\mathrm{H}_{2}$, provide remarkable insights to understand the effects underlying the predicted stabilization of the $\mathrm{P}-\mathrm{H}$ systems under high-pressure conditions.

Finally, the synthesis of $\left(\mathrm{PH}_{3}\right)_{2} \mathrm{H}_{2}$ effectively provides confirmatory experimental evidence for the key role played by $\mathrm{H}_{2}$ molecules in stabilizing the $\mathrm{PH}$ system at high pressure, as suggested by recent calculations predicting the presence of $\mathrm{H}_{2}$ units in superconducting $\mathrm{PH}$ structures at high pressure.

Once again the history of phosphorus has intertwined with pressure, whose role in enhancing similarities and consistencies in the periodic properties of elements apparently exhibiting particular behavior at ambient conditions ${ }^{5,66,67}$ is here further highlighted.

\section{Methods}

Synthesis of $\mathbf{P}_{\text {black }}$. Pure crystalline $\mathrm{P}_{\text {black }}$ was synthesized from red phosphorus according to reference ${ }^{68}$. All the reactants used for the synthesis of $P_{\text {black }}$ were purchased from Sigma-Aldrich with the following purity: red phosphorus $(>99.99 \%)$, tin $(>99.999 \%)$, gold $(>99.99 \%)$, and $\mathrm{SnI}_{4}(99.999 \%)$. The purity of the synthesized $\mathrm{P}_{\text {black }}$ crystals was checked by X-ray powder diffraction, Raman spectroscopy, EDX analysis and ICP-MS measurements, the latter giving a purity of $99.999+\%$. The crystals of $\mathrm{P}_{\text {black }}$ were fragmented by means of a metallic tip for obtaining smaller $20-40 \mu \mathrm{m}$ chips to be loaded into the DAC.

\footnotetext{
Sample preparation and the experimental conditions. Pressure was generated by means of membrane Diamond Anvil Cells (DAC) equipped with Ia type standard cut 16 -sided beveled anvils having $600 \mu \mathrm{m}$ culets. Re gaskets $200 \mu \mathrm{m}$ thick were indented to $80 \mu \mathrm{m}$ thickness and laser-drilled to obtain a $300 \mu \mathrm{m}$ sample chamber. Before using them for the sideways containment of the samples, a Au ring was applied to prevent unintended catalytic effect and $\mathrm{H}_{2}$ diffusion and reactivity with Re. For this purpose the $300 \mu \mathrm{m}$ diameter gasket hole was filled with Au powder, compressed with $\sim 20$ bar of $\mathrm{He}$ in the membrane until the powder appeared reflective and then laser-drilled again to obtain a $250 \mu \mathrm{m}$ diameter hole. A small crystal of $\mathrm{P}_{\text {black }}$ was placed in the sample chamber by means of a metallic tip and the remaining volume was filled with fluid $\mathrm{H}_{2}$ using standard gas-loading technique. $\mathrm{Au}$ and a ruby chip were used to measure the pressure, whereas the temperature was measured by the fit of the black body thermal radiation emission of the sample during laser heating. High temperature was generated by means of $\mathrm{Nd}$ : YAG laser source $(\lambda=1064 \mathrm{~nm})$ focused on the $\mathrm{P}_{\text {black }}$ crystal $(\approx 30 \mu \mathrm{m}$ beam spot size diameter), which acted both as reactant and laser absorber, thus avoiding any
}

other source of contamination. No evidence for the formation of $\mathrm{Au}^{69}$ or $\mathrm{Re}^{70}$ hydrides was observed.

X-ray diffraction data acquisition and analysis. XRD experiments were carried out at the ESRF-ID27 beamline using a monochromatic synchrotron radiation beam $(\lambda=0.3738 \AA)$ focused to $\sim 5 \mu \mathrm{m}$ to select different areas of the heterogeneous sample. The diffracted radiation was revealed by a MAR CCD165 detector, located approximately at $187 \mathrm{~mm}$ from the sample. The setup was calibrated against a $\mathrm{CeO}_{2}$ powder standard and Dioptas software was used to integrate the $2 \mathrm{D}$ area images to $1 \mathrm{D}$ patterns.

A single-crystal data set was collected at $5.5 \mathrm{GPa}$. Diffraction intensities were acquired in an $\omega$-oscillation scan mode over the range $\pm 30^{\circ}$ with a frame width of $0.5^{\circ}$ and an exposure time of $2 \mathrm{~s}$ per single frame. The instrument model was calibrated at the beginning of the beam time by performing a full data collection of an enstatite single-crystal placed in a dummy DAC. The diffraction images were then imported into a CrysAlisPro suite (Supplementary Note 1) and processed accordingly. After determining the unit cell the intensities were reduced applying corrections for Lorentz and polarization effects, and also a multiscan absorption correction at the final step. Reciprocal lattice layers were reconstructed using the unwarp procedure (Supplementary Fig. 1). Careful inspection of the unwarped images did not reveal any twinning, satellite reflections or diffuse scattering, in contrast to the crystal of $\left(\mathrm{H}_{2} \mathrm{Se}\right)_{2} \mathrm{H}_{2}$, where diffuse scattering streaks were observed $^{27}$. The crystal structure was subsequently solved by direct methods and then refined on $\mathrm{F}^{2}$ by full-matrix least-squares procedures using the SHELXL package (Supplementary Note 1). In addition, at the same pressure and at two other pressure points ( 4.1 and $4.5 \mathrm{GPa})$, panoramic oscillation images $\left(\phi= \pm 5^{\circ}\right.$, acquisition time $30 \mathrm{~s}$ ) of oligocrystalline conglomerate were recorded and used to perform Le Bail fits with JANA 2006 software after azimuthal integration (Supplementary Figs. 2-4).

Spectroscopic data acquisition and analysis. The Raman spectra were acquired at LENS with $1.5 \mathrm{~cm}^{-1}$ spectral resolution using the $647.1 \mathrm{~nm}$ emission wavelengths of a $\mathrm{Kr}$ ion laser. The details of the Raman setup are described elsewhere ${ }^{71}$. Raman spectra were acquired performing a $14 \times 14$ mapping over a $10 \mu \mathrm{m}$ spaced grid using a single 300 groove/mm grating, which allowed to cover the $200-3300 \mathrm{~cm}^{-1}$ frequency region with $4 \mathrm{~cm}^{-1}$ spectral resolution. The most significant spots of the mapping were further inspected at higher resolution $\left(1.5 \mathrm{~cm}^{-1}\right)$ with different grating configuration down to $23.5 \mathrm{~cm}^{-1}$ (triple grating subtractive configuration 900-900-1800 groove/ $\mathrm{mm}$ ) and up to $4700 \mathrm{~cm}^{-1}$ (single grating configuration 900 groove/mm). No photochemical effect was observed at the employed laser power $(1.5 \mathrm{~mW})$ for pressure higher than $1.9 \mathrm{GPa}$, whereas at this pressure the formation of $\mathrm{P}_{\text {black }}$ could indicate the decomposition of $\mathrm{PH}_{3}{ }^{55}$.

The FTIR spectra were acquired with $1 \mathrm{~cm}^{-1}$ spectral resolution, using a Bruker IFS-120HR interferometer, suitably modified for the acquisition of infrared absorption spectra at high pressure in $\mathrm{DAC}^{72}$.

The frequency and intensity of the FTIR and Raman bands were obtained by fitting procedure using Voigt line shapes after baseline subtraction. Fityk software was used for this purpose.

\section{Data availability}

The X-ray crystallographic coordinates for the structure of the $\left(\mathrm{PH}_{3}\right)_{2}$ vdW compound reported in this study have been deposited at the Cambridge Crystallographic Data Centre (CCDC), under deposition number 2034375. These data can be obtained free of charge from The Cambridge Crystallographic Data Centre via www.ccdc.cam.ac.uk/ datarequest/cif. All other data that support the findings of this study are available from the corresponding author upon reasonable request.

Received: 7 March 2020; Accepted: 14 October 2020; Published online: 30 November 2020

\section{References}

1. Bridgman, P. W. Two new modifications of phosphorus. J. Am. Chem. Soc. 36, 1344-1363 (1914).

2. Corbridge, D. Phosphorus: Chemistry, Biochemistry and Technology, Sixth Edition. (Taylor \& Francis, 2013).

3. Jamieson, J. C. Crystal structures adopted by black phosphorus at high pressures. Science 139, 1291-1292 (1963).

4. Scelta, D. et al. Interlayer bond formation in black phosphorus at high pressure. Angew. Chem. Int. Ed. 56, 14135-14140 (2017).

5. Scelta, D. et al. The p-sc structure in phosphorus: bringing order to the high pressure phases of group 15 elements. Chem. Commun. 54, 10554-10557 (2018).

6. Peruzzini, M. et al. A perspective on recent advances in phosphorene functionalization and its applications in devices. Eur. J. Inorg. Chem. 2019, 1476-1494 (2019). 
7. Ryder, C. R. et al. Covalent functionalization and passivation of exfoliated black phosphorus via aryl diazonium chemistry. Nat. Chem. 8, 597-602 (2016).

8. Bódi, D. \& Höltzl, T. Thermal stability and flexibility of hydrogen terminated phosphorene nanoflakes. J. Phys. Chem. C. 122, 8535-8542 (2018).

9. Mao, H.-K., Chen, X.-J., Ding, Y., Li, B. \& Wang, L. Solids, liquids, and gases under high pressure. Rev. Mod. Phys. 90, 015007 (2018).

10. Citroni, M., Ceppatelli, M., Bini, R. \& Schettino, V. Laser-induced selectivity for dimerization versus polymerization of butadiene under pressure. Science 295, 2058-2060 (2002)

11. Chelazzi, D., Ceppatelli, M., Santoro, M., Bini, R. \& Schettino, V. Highpressure synthesis of crystalline polyethylene using optical catalysis. Nat. Mater. 3, 470-475 (2004).

12. Dong, X. et al. A stable compound of helium and sodium at high pressure. Nat. Chem. 9, 440-445 (2017).

13. Dewaele, A. et al. Synthesis and stability of xenon oxides $\mathrm{Xe}_{2} \mathrm{O}_{5}$ and $\mathrm{Xe}_{3} \mathrm{O}_{2}$ under pressure. Nat. Chem. 8, 784-790 (2016).

14. Howie, R. T., Turnbull, R., Binns, J., Frost, M., Dalladay-Simpson, P. \& Gregoryanz, E. Formation of xenon-nitrogen compounds at high pressure. Sci. Rep. 6, 34896 (2016).

15. Wang, H., Li, X., Gao, G., Li, Y. \& Ma, Y. Hydrogen-rich superconductors at high pressures. Wiley Interdiscip. Rev. Comput. Mol. Sci. 8, el330 (2018).

16. Mao, W. L. \& Mao, H.-k. Hydrogen storage in molecular compounds. Proc. Natl Acad. Sci. USA 101, 708-710 (2004).

17. Struzhkin, V. V., Militzer, B., Mao, W. L., Mao, H.-K. \& Hemley, R. J. Hydrogen storage in molecular clathrates. Chem. Rev. 107, 4133-4151 (2007).

18. Vos, W. L. et al. A high-pressure van der Waals compound in solid nitrogenhelium mixtures. Nature 358, 46-48 (1992).

19. Somayazulu, M. S., Finger, L. W., Hemley, R. J. \& Mao, H. K. High-pressure compounds in methane-hydrogen mixtures. Science 271, 1400-1402 (1996).

20. Strobel, T. A., Somayazulu, M. \& Hemley, R. J. Novel pressure-induced interactions in silane-hydrogen. Phys. Rev. Lett. 103, 065701 (2009).

21. Strobel, T. A., Chen, X.-J., Somayazulu, M. \& Hemley, R. J. Vibrational dynamics, intermolecular interactions, and compound formation in $\mathrm{GeH}_{4}-\mathrm{H}_{2}$ under pressure. J. Chem. Phys. 133, 164512 (2010).

22. Laniel, D., Svitlyk, V., Weck, G. \& Loubeyre, P. Pressure-induced chemical reactions in the $\mathrm{N}_{2}\left(\mathrm{H}_{2}\right)_{2}$ compound: from the $\mathrm{N}_{2}$ and $\mathrm{H}_{2}$ species to ammonia and back down into hydrazine. Phys. Chem. Chem. Phys. 20, 4050-4057 (2018).

23. Ciezak, J. A., Jenkins, T. A. \& Hemley, R. J. Optical and Raman microspectroscopy of nitrogen and hydrogen mixtures at high pressure. AIP Conf. Proc. 1195, 1291-1294 (2009).

24. Loubeyre, P. \& LeToullec, R. Stability of $\mathrm{O}_{2} / \mathrm{H}_{2}$ mixtures at high pressure. Nature 378, 44-46 (1995).

25. Vos, W. L., Finger, L. W., Hemley, R. J. \& Mao, H.-K. Novel $\mathrm{H}_{2}-\mathrm{H}_{2} \mathrm{O}$ clathrates at high pressures. Phys. Rev. Lett. 71, 3150-3153 (1993).

26. Strobel, T. A., Ganesh, P., Somayazulu, M., Kent, P. R. C. \& Hemley, R. J. Novel cooperative interactions and structural ordering in $\mathrm{H}_{2} \mathrm{~S}-\mathrm{H}_{2}$. Phys. Rev. Lett. 107, 255503 (2011)

27. Pace, E. J. et al. Synthesis and stability of hydrogen selenide compounds at high pressure. J. Chem. Phys. 147, 184303 (2017).

28. Binns, J. et al. Synthesis and stability of hydrogen iodide at high pressures. Phys. Rev. B 96, 144105 (2017).

29. Ulivi, L., Bini, R., Loubeyre, P., LeToullec, R. \& Jodl, H. J. Spectroscopic studies of the $\operatorname{Ar}\left(\mathrm{H}_{2}\right)_{2}$ compound crystal at high pressure and low temperatures. Phys. Rev. B 60, 6502-6512 (1999).

30. Kleppe, A. K., Amboage, M. \& Jephcoat, A. P. New high-pressure van der Waals compound $\mathrm{Kr}\left(\mathrm{H}_{2}\right)_{4}$ discovered in the krypton-hydrogen binary system. Sci. Rep. 4, 4989 (2014).

31. Somayazulu, M. et al. Pressure-induced bonding and compound formation in xenon-hydrogen solids. Nat. Chem. 2, 50-53 (2010).

32. Somayazulu, M., Dera, P., Smith, J. \& Hemley, R. J. Structure and stability of solid $\mathrm{Xe}\left(\mathrm{H}_{2}\right)_{n}$. J. Chem. Phys. 142, 104503 (2015).

33. Bi, T., Zarifi, N., Terpstra, T. \& Zurek, E. Reference Module in Chemistry, Molecular Sciences and Chemical Engineering. (Elsevier, 2019)

34. Drozdov, A. P., Eremets, M. I., Troyan, I. A., Ksenofontov, V. \& Shylin, S. I. Conventional superconductivity at 203 kelvin at high pressures in the sulfur hydride system. Nature 525, 73-83 (2015).

35. Bardeen, J., Cooper, L. N. \& Schrieffer, J. R. Microscopic theory of superconductivity. Phys. Rev. 106, 162-164 (1957).

36. Drozdov, A. P. \& Troyan, M. I. E. Superconductivity above $100 \mathrm{~K}$ in $\mathrm{PH}_{3}$ at high pressures. Preprint at https://arxiv.org/abs/1508.06224.

37. Flores-Livas, J. A. et al. Superconductivity in metastable phases of phosphorus-hydride compounds under high pressure. Phys. Rev. B 93, 020508 (2016).

38. Shamp, A. et al. Decomposition products of phosphine under pressure: $\mathrm{PH}_{2}$ stable and superconducting? J. Am. Chem. Soc. 138, 1884-1892 (2016).
39. Bi, T., Miller, D. P., Shamp, A. \& Zurek, E. Superconducting phases of phosphorus hydride under pressure: stabilization by mobile molecular hydrogen. Angew. Chem. Int. Ed. 56, 10192-10195 (2017).

40. Morton, R. J. \& Kaiser, R. I. Kinetics of suprathermal hydrogen atom reactions with saturated hydrides in planetary and satellite atmospheres. Planet. Space Sci. 51, 365-373 (2003).

41. Lewis, J. S. Physics and Chemistry of the Solar System. in International Geophysics, Vol. 87. (Academic Press, 2004)

42. Fletcher, L., Orton, G., Teanby, N. \& Irwin, P. Phosphine on Jupiter and Saturn from Cassini/CIRS. Icarus 202, 543-564 (2009).

43. Pasek, M. A., Mousis, O. \& Lunine, J. I. Phosphorus chemistry on Titan. Icarus 212, 751-761 (2011).

44. Mao, H. K. \& Bell, P. M. Observations of hydrogen at room temperature $\left(25^{\circ} \mathrm{C}\right)$ and high pressure (to 500 Kilobars). Science 203, 1004-1006 (1979).

45. Cotton, F. A., Wilkinson, G., Murillo, C. A. \& Bochmann, M. Advanced inorganic chemistry, 6th edn. (John Wiley \& Sons, 1999).

46. Atkins, P., Overton, T., Rourke, J., Weller, M. \& Armstrong, F. Shriver and Atkins' Inorganic Chemistry, 5th edn. (W. H. Freeman, 2010).

47. Natta, G. \& Casazza, E. La struttura dellidrogeno fosforato (PH3) e dell'idrogeno arsenicale $\left(\mathrm{AsH}_{3}\right)$. Gazz. Chim. Ital. 60, 851-859 (1930)

48. Stevenson, D. P. The structure of phosphine and related hydrides. J. Chem. Phys. 8, 285-287 (1940).

49. Bondi, A. Van der Waals volumes and radii. J. Phys. Chem. 68, 441-451 (1964).

50. Hardin, A. H. \& Harvey, K. B. Infrared absorption of solid phosphine. Can. J. Chem. 42, 84-89 (1964)

51. Francia, M. D. \& Nixon, E. R. Infrared study of solid phosphine. J. Chem. Phys. 58, 1061-1065 (1973).

52. Devyatykh, G. G., Sennikov, P. G. \& Nabiev, S. S. Vibrational spectra of volatile inorganic hydrides in the liquid state. Russ. Chem. Bull. 48, 623-639 (1999).

53. Baudler, M. \& Glinka, K. Open-chain polyphosphorus hydrides (Phosphines). Chem. Rev. 94, 1273-1297 (1994).

54. Ceppatelli, M., Bini, R. \& Schettino, V. High-pressure photodissociation of water as a tool for hydrogen synthesis and fundamental chemistry. Proc. Nat Acad. Sci. USA 106, 11454-11459 (2009).

55. Yuan, Y. et al. Stoichiometric evolutions of $\mathrm{PH}_{3}$ under high pressure: implication for high- $\mathrm{T}_{c}$ superconducting hydrides. Natl Sci. Rev. 6, 524-531 (2019).

56. Mao, H., Xu, J. \& Bell, P. Pressure-Induced Infrared Spectra of Hydrogen to 542 kbar. Year book, Vol. 82, 366-372 (Carnegie Institution of Washington, 1983)

57. Binns, J., Dalladay-Simpson, P., Wang, M., Ackland, G. J., Gregoryanz, E. \& Howie, R. T. Formation of $\mathrm{H}_{2}$-rich iodine-hydrogen compounds at high pressure. Phys. Rev. B 97, 024111 (2018).

58. Pace, E. J. et al. Properties and phase diagram of $\left(\mathrm{H}_{2} \mathrm{~S}\right)_{2} \mathrm{H}_{2}$. Phys. Rev. B, 101, 174511 (2020).

59. Snider, E. et al. Room-temperature superconductivity in a carbonaceous sulfur hydride. Nature 586, 373-377 (2020).

60. Hansen, A. S., Du, L. \& Kjaergaard, H. G. Positively charged phosphorus as a hydrogen bond acceptor. J. Phys. Chem. Lett. 5, 4225-4231 (2014).

61. Grabowski, S. J., Alkorta, I. \& Elguero, J. Complexes between dihydrogen and amine, phosphine, and arsine derivatives. hydrogen bond versus pnictogen interaction. J. Phys. Chem. A 117, 3243-3251 (2013).

62. Guńka, P. A., Hapka, M., Hanfland, M., Chalasiński, G. \& Zachara, J. Toward heterolytic bond dissociation of dihydrogen: the study of hydrogen in arsenolite under high pressure. J. Phys. Chem. C. 123, 16868-16872 (2019).

63. Hoffmann, R. How chemistry and physics meet in the solid state. Angew. Chem. Int. Ed. 26, 846-878 (1987).

64. Liu, M. et al. Unravelling decomposition products of phosphine under high pressure. J. Raman Spectrosc. 49, 721-727 (2018).

65. Greaves, J. S. et al. Phosphine gas in the cloud decks of Venus. Nat. Astron. https://doi.org/10.1038/s41550-020-1174-4 (2020).

66. Lundegaard, L. F., Weck, G., McMahon, M. I., Desgreniers, S. \& Loubeyre, P. Observation of an $\mathrm{O}_{8}$ molecular lattice in the $\epsilon$ phase of solid oxygen. Nature 443, 201-204 (2006).

67. Santoro, M. et al. Amorphous silica-like carbon dioxide. Nature 441, 857-860 (2006).

68. Nilges, T., Kersting, M. \& Pfeifer, T. A fast low-pressure transport route to large black phosphorus single crystals. J. Solid State Chem. 181, 1707-1711 (2008).

69. Donnerer, C., Scheler, T. \& Gregoryanz, E. High-pressure synthesis of noble metal hydrides. J. Chem. Phys. 138, 134507 (2013).

70. Atou, T. \& Badding, J. In situ diffraction study of the formation of rhenium hydride at high pressure. J. Solid State Chem. 118, 299-302 (1995).

71. Ceppatelli, M., Gorelli, F. A., Haines, J., Santoro, M. \& Bini, R. Probing highpressure reactions in heterogeneous materials by raman spectroscopy. Z. Krist. Cryst. Mater. 229, 83-91 (2014). 
72. Bini, R., Ballerini, R., Pratesi, G. \& Jodl, H. J. Experimental setup for Fourier transform infrared spectroscopy studies in condensed matter at high pressure and low temperatures. Rev. Sci. Instrum. 68, 3154-3160 (1997).

73. Bonev, S. A., Schwegler, E., Ogitsu, T. \& Galli, G. A quantum fluid of metallic hydrogen suggested by first-principles calculations. Nature 431, 669-672 (2004).

74. Batsanov, S. S. Van der Waals radii of hydrogen in gas-phase and condensed molecules. Struct. Chem. 10, 395-400 (1999).

75. Albright, A. T., Burdett, J. K. \& Whangbo, M.-H. Orbital Interactions in Chemistry, 2nd Edn, 834 (Wiley, 2013).

\section{Acknowledgements}

Thanks are expressed to EC through the European Research Council (ERC) for funding the project PHOSFUN "Phosphorene functionalization: a new platform for advanced multifunctional materials" (Grant Agreement No. 670173) through an ERC Advanced Grant. This study was supported by the Deep Carbon Observatory (DCO) initiative under the project Physics and Chemistry of Carbon at Extreme Conditions, by the project "GreenPhos - alta pressione", by the Italian Ministero dell'Istruzione, dell'Università e della Ricerca (MIUR), by Ente Cassa di Risparmio di Firenze under the project Firenze Hydrolab2.0 and by Fondazione Cassa di Risparmio di Firenze under the project HP-PHOTOCHEM. The authors acknowledge the European Synchrotron Radiation Facility (ESRF) for provision of synchrotron radiation facilities and thank G. Garbarino, M. Mezouar and J. Jacobs for assistance in using beamline ID27. The authors would like to thank Prof. Roberto Righini for useful discussions.

\section{Author contributions}

M.C., D.S., and R.B. performed the experiments, analyzed all the data and discussed the results. K.D. analyzed the XRD data and discussed the results. M.S.R and M.P discussed the results. M.S.R. synthesized black phosphorus. G.G., J.J., and M.M. assisted at ESRFID27. M.C. conceived the experiment and wrote the article.

\section{Competing interests}

The authors declare no competing interests.

\section{Additional information}

Supplementary information is available for this paper at https://doi.org/10.1038/s41467020-19745-2.

Correspondence and requests for materials should be addressed to M.C.

Peer review information Nature Communications thanks the anonymous reviewers for their contribution to the peer review of this work. Peer reviewer reports are available.

Reprints and permission information is available at http://www.nature.com/reprints

Publisher's note Springer Nature remains neutral with regard to jurisdictional claims in published maps and institutional affiliations.

(c) (i) Open Access This article is licensed under a Creative Common Attribution 4.0 International License, which permits use, sharing, adaptation, distribution and reproduction in any medium or format, as long as you give appropriate credit to the original author(s) and the source, provide a link to the Creative Commons license, and indicate if changes were made. The images or other third party material in this article are included in the article's Creative Commons license, unless indicated otherwise in a credit line to the material. If material is not included in the article's Creative Commons license and your intended use is not permitted by statutory regulation or exceeds the permitted use, you will need to obtain permission directly from the copyright holder. To view a copy of this license, visit http://creativecommons.org/ licenses/by/4.0/.

(C) The Author(s) 2020 